\title{
The Effects of Noncontact Cleaners on Transparent Solar Materials
}

H. L. Hampton

M. A. Lind

April 1979

Prepared for the U.S. Department of Energy under Contract EY-76-C-06-1830

Pacific Northwest Laboratory Operated for the U.S. Department of Energy by Battelle Memorial Institute 


\title{
NOTICE
}

This report was prepared as an account of work sponsored by the United States Government. Neither the United States nor the Department of Energy, nor any of their employees, nor any of their contractors, subcontractors, or their employees, makes any warranty, express or implied, or assumes any legal liability or responsibility for the accuracy, completeness or usefulness of any information, apparatus, product or process disclosed, or represents that its use would not infringe privately owned rights.

The views, opinions and conclusions contained in this report are those of the contractor and do not necessarily represent those of the United States Government or the United States Department of Energy.

\author{
PACIFIC NORTHWEST LABORATORY \\ operated by \\ BATTELLE \\ for the \\ UNITED STATES DEPARTMENT OF ENERGY \\ Under Contract EY-76-C-06-1830
}

\author{
Printed in the United States of America \\ Available from \\ National Technical Information Service \\ United States Department of Commerce \\ 5285 Port Royal Road \\ Springfield, Virginia 22151 \\ Price: Printed Copy $\$$ \\ $\because$ Microfiche $\$ 3.00$ \\ NTIS \\ -Pages Selling Price \\ 001-025 $\quad \$ 4.00$ \\ 026-050 $\quad \$ 4.50$ \\ 051-075 $\$ 5.25$ \\ 076-100 $\quad \$ 6.00$ \\ $101-125 \quad \$ 6.50$ \\ $126-150 \quad \$ 7.25$ \\ $151-175 \quad \$ 8.00$ \\ $176-200 \quad \$ 9.00$ \\ 201-225 $\quad \$ 9.25$ \\ 226-250 $\quad \$ 9.50$ \\ $251-275 \quad \$ 10.75$ \\ $276-300 \quad \$ 11.00$
}


PNL-2969

UC -62

\section{5}

THE EFFECTS OF NONCONTACT CLEANERS

ON TRANSPARENT SOLAR MATERIALS

H. L. Hampton

M. A. Lind

Apri1 1979

Prepared for

U.S. Department of Energy

Under Contract EY-76-C-06-1830

Pacific Northwest Laboratory

Richland, Washington 99352 


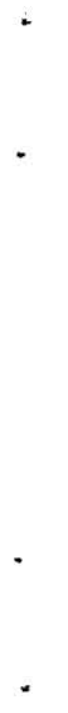

- 


\section{ABSTRACT}

A brief study has been undertaken to evaluate the performance of noncontact cleaning agents for use on solar collectors. Several techniques are used to compare cleansing agents which have been recommended by their respective manufacturers for cleaning solar mirrors. Wetting and residue buildup properties are evaluated for over 50 of these commercially available cleaners. The wetting properties of each cleaner are evaluated by measuring the growth of the contact area of a constant volume drop as a function of time. Losses due to residue buildup are solar weighted and considered equally with the wetting parameters and cost figures to construct a figure of merit for cleaner comparison. 


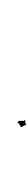

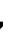




\section{CONTENTS}

ABSTRACT . . . . . . . . . . . . . . . . . . . . . . . .

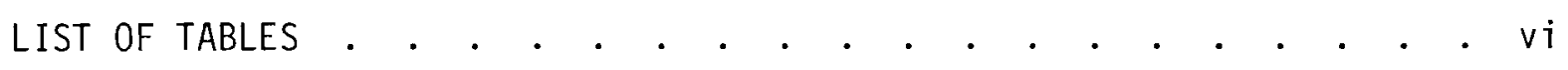

LIST OF FIGURES . . . . . . . . . . . . . . . . . . . . . . vii

INTRODUCTION . . . . . . . . . . . . . . . . . . . . . . 1

CONCLUSIONS . . . . . . . . . . . . . . . . . . . . . 3

SURFACE WETTING STUDIES . . . . . . . . . . . . . . . . . . . . . 5

Background . . . . . . . . . . . . . . 5

Instrumentation . . . . . . . . . . . . . . . . . 8

Preliminary Wetting Investigations on Glass. . . . . . . 8

Cleaners on Glass Substrates. . . . . . . . . . . 16

Cleaners on Plastic Substrates . . . . . . . . . . 17

RESIDUE STUDIES . . . . . . . . . . . . . . . . . 35

Background . . . . . . . . . . . . . . . . . . 35

Instrumentation . . . . . . . . . . . . . . . . . 35

Residue on Glass Substrates . . . . . . . . . . . 37

FIGURE OF MERIT . . . . . . . . . . . . . . . . . . . . . 41

Background . . . . . . . . . . . . . . . . . 41

Results for Glass Cleaners . . . . . . . . . . . 42 ACKNOWLEDGMENTS . . . . . . . . . . . . . . . . . . . 45

APPENDIX A - Manufacturers and Distributors of Glass Cleaners . . A

APPENDIX B - Manufacturers and Distributors of Plastics Cleaners . . B1

APPENDIX $\mathrm{C}$ - The t-Test . . . . . . . . . . . . . . . $c 1$ 


\section{LIST OF TABLES}

1 Wetting of float Glass . . . . . . . . . . . . 13

2 Wetting of Drawn Glass . . . . . . . . . . . . . . 14

3 Wetting of Fusion Glass. . . . . . . . . . . . 15

4 Relative Wetting Data for Selected Cleaning Agents on Glass . . . . . . . . . . . . . . . . . . 20

5 Relative Wetting Data for Selected Cleaning Agents on Acrylic . . . . . . . . . . . . . . . . . . . 27

6 Relative Wetting Data for Selected Cleaning Agents on Polycarbonate. . . . . . . . . . . . . . . . . 28

7 Relative Wetting Data for Selected Cleaning Agents on Polyester . . . . . . . . . . . . . . . . . . 29

8 Relative Wetting Data for Selected Cleaning Agents on Polyvinylfluoride. . . . . . . . . . . . . . . . 30

9 Transmittance Losses Due to Residue Buildup of Glass Cleaners After Repeated Application. . . . . . . . . 38

10 Cleaning Solution Cost and Relative Figure of Merit . . . . . 43 


\section{LIST OF FIGURES}

1 Block Diagram of Surface Wetting Area Measurement Instrument . . . 9

2 Optical Configuration for SWAMI . . . . . . . . . . . . . 10

3 Typical Video Image of a Fairly Symmetrical Drop

from the Array Detector, as Seen on a CRT Monitor . . . . . . 10

4 Wetting Characteristics for Selected Cleaners on Glass . . . . . 18

5 Wetting Characteristics for Selected Cleaners on Glass . . . . 19

6 Scatter Diagram of Wetting Parameters for

Selected Cleaners on Glass . . . . . . . . . . . . . . . . . 21

7 Wetting Characteristics of Selected Cleaners

on Acrylic . . . . . . . . . . . . . . . . . . . . 23

8 Wetting Characteristics of Selected Cleaners
on Polycarbonate . . . . . . . . . . . . . . . . . . . . . . . 24

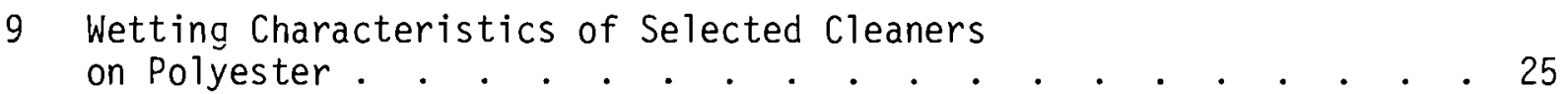

10 Wetting Characteristics of Selected Cleaners

11 Scatter Diagram of Wetting Parameters for

Selected Cleaners on Acryic . . . . . . . . . . . . . . . . 31

12 Scatter Diagram of Wetting Parameters for

Selected Cleaners on Polycarbonate . . . . . . . . . . . 32

13 Scatter Diagram of Wetting Parameters for

Selected Cleaners on Polyester . . . . . . . . . . . . . . 33

14 Scatter Diagram of Wetting Parameters for

15 Photograph of Cleaner Residue Deposition Apparatus . • . • . . 36

16 Figure of Merit for Glass Cleaners Used in

Noncontact Cleaning in Solar Application . . . . . . . . . 44 
$\checkmark$ 


\section{INTRODUCTION}

The problems associated with cleaning solar materials have been largely ignored. Dirt accumulations have been shown to reduce the transmittance of glass by as much as $50 \%$ in only 14 days. ${ }^{1}$ The effects on plastic may be even worse due to the dust-attracting and adhesive properties of the polymeric surface constructions. Various strategies to overcome the problems of dirt and dust accumulations have been suggested. Options considered fall into three basic categories: 1) enlarging the collector field to compensate for the optical losses, 2) preventing the contaminants from depositing on the collector surface in sufficient quantities to significantly degrade performance, and 3 ) periodic removal of the atmospheric contaminants by cleaning.

This report focuses on one aspect of the third strategy, the comparison of cleaning agents which have potential application in noncontact cleaning schemes. The noncontact cleaning approach is desirable because of the advantages it offers when maintaining complex collector shapes and large surface areas characteristic of the solar industry. A noncontact cleaning strategy such as high pressure spray minimizes surfaces abrasions and is usually less manpower intensive and therefore less costly than conventional techniques which involve mechanical contact with the surface.

The evaluation of cleaning agents is subject to numerous interpretations, depending upon the point of view of the evaluator. A single unbiased test to compare or rank cleaning agents which relates to all applications has yet to be developed. As a practical concern, only a limited number of parameters can be investigated in an expeditious manner.

The surface chemistry between the cleaner and the material being cleaned is one of the factors that determine the overall effectiveness of the cleaner. One convenient way to evaluate this surface interaction without examining the chemistry in detail is to look at how the cleaner wets the surface to

${ }^{1}$ H. P. Garg, "Effect of Dirt on Transparent Covers in Flat Plate Solar Energy Collectors," Solar Energy 15:299-302 (1974). 
which it is applied. The surface wetting can be characterized by using two parameters directly applicable to the cleaning process. These parameters are the maximum area wetted by a constant volume of the cleaner and the time it takes to obtain a given fraction of this area.

Two other important parameters for cleaner evaluation are the effects of repeated application and the cost of the product. Repeated applications of a cleaner may cause excessive residue buildup, resulting in solar absorption or scattering, thus reducing collector performance. High cost cleaners could add significantly to the life cycle operations and maintenance cost of the solar collector field.

In this report the wetting, residue buildup and cost parameters have been used to construct an arbitrary, but useful, figure of merit for comparing cleaners. The report, which is the result of a brief study conducted for DOE, is not intended to be a definitive study of the cleaners. Rather, its purpose is to present methods of evaluation that may be useful when comparing cleaning products. No attempt has been made to do an exhaustive study of all the available cleaning agents or to make definitive statements about any particular product.

As a word of caution, some discretion should be exercised when interpreting the results of the tests described in this report. The evaluation of any cleaning agent using these techniques may be influenced by any number of external parameters. Examples of these parameters include: 1) variations in the surface of the material to which the cleaner is applied, 2) non-uniform preparation of the surface before testing, and 3) batch variations in the cleaner being tested. Each of these parameters can cause errors which are large enough to invalidate the results obtained in many comparative types of studies. Although attempts have been made to minimize the effects of these parameters in this study, they cannot be totally eliminated.

4 large number of firms manufacturing or distributing glass and plastic cleaners were contacted. The initial list of contacts was generated from the Thomas Register under the categories of "Cleaners: Glass" and "Cleaners: Plastic." A listing of the firms contacted is contained in Appendices A and B. 


\section{CONCLUSIONS}

The wetting characteristics of a number of glass and plastic cleaners have been compared. The contact area of a fixed volume of the cleaning solution has been measured as a function of time on various substrate materials. The effects on the solar transmittance of the substrates after repeated application have been estimated. These parameters have been combined with the prepared cost per gallon to formulate a figure of merit for the cleaners based on a specific noncontact cleaning scheme for solar applications. 


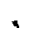




\section{SURFACE WETTING STUDIES}

\section{Background}

One method for comparing cleaning solutions is to determine their ability to wet the surface of the material to be cleaned. The wetting of a solid surface with a liquid is, with few exceptions, a function of the difference in surface energy between the liquid and the solid. Surface wetting is generally quantified by measuring the contact angle between the drop surface and the solid surface. The contact angle is defined as the exterior angle between the tangent to the drop surface, at the point of contact, and the plane of the solid surface on which the drop is placed.

Unfortunately, accurate measurements of contact angle are difficult to perform and the results become somewhat subjective. However, several alternative parameters can be measured when relative rather than absolute comparisons are desirable. One useful technique is to measure the diameter of the wetted surface for a given volume of applied liquid. This technique is easier to implement than contact angle measurements, but is still subject to error introduced when the contacted area is non-isotropic.

A preferred technique is to measure the area of the wetted surface for a given volume of applied liquid. With appropriate instrumentation, this measurement is rapid, accurate, and easy to perform. Such instrumentation is described later in this document.

The actual measurement of contact area is complicated by the fact that the area may vary with time. A given volume of 1 iquid will tend to spread over the solid surface from the time it is placed on the surface until some equilibrium value is reached. The two parameters of interest for the wetting study are the time constant for this interaction and the final wetted area.

With a few exceptions, the time dependence of the area growth can be fit to the following exponential function:

$$
A=\left(A_{f}-A_{j}\right)\left[1-e^{-\beta t}\right]+A_{i},
$$


where $A$ is the drop area, $t$ is the elapsed time, $B$ is the inverse of the time constant for the process, $A_{f}$ is the asymptotic value of the area reached at an infinite time, assuming no evaporation occurs, and $A_{i}$ is the initial drop area at $t=0$. Exceptions to the above equation include alcohol based cleaners that evaporate before an equilibrium value for the area is reached.

It is impractical to measure the actual values for the initial and final areas for most real cleaning agents. The initial areas are a strong function of the exact mechanism used to place the drops on the surface. The final area is unattainable in a reasonable evaluation period because time constants may be on the order of tens of minutes.

The time constant can be calculated from Equation (1) without reference to the actual initial and final areas by measuring the contact area of the drop at four intermediate times. One can see that

$$
\frac{A_{1}-A_{2}}{A_{3}-A_{4}}=\frac{e^{-\beta t_{2}}-e^{-\beta t_{3}}}{e^{-\beta t_{4}}-e^{-\beta t_{3}}}
$$

where $A_{1}$ to $A_{4}$ are the areas at times $t_{1}$ to $t_{4}$. If one assumes, in addition, that the four measurements are taken at equal time intervals, $\Delta t$, then Equation (2) reduces to:

$$
\begin{aligned}
\frac{A_{1}-A_{2}}{A_{3}-A_{4}} & =\frac{e^{-\beta\left(t_{1}+\Delta t\right)}-e^{-\beta t_{1}}}{e^{-\beta\left(t_{1}+3 \Delta t\right)}-e^{-\beta\left(t_{1}+2 \Delta t\right)}} \\
& =\frac{e^{-\beta \Delta t}-1}{e^{-3 \beta \Delta t}-e^{-2 \beta \Delta t}} \\
& =e^{2 \beta \Delta t} .
\end{aligned}
$$

Solving for $\beta$, one finds

$$
\beta=\frac{1}{2 \Delta t} \ln \left(\frac{A_{1}-A_{2}}{A_{3}-A_{4}}\right) .
$$


Once the time constant is known, the final area can be calculated. By rearranging Equation (1), one can write

$$
A_{f}-A=\left(A_{f}-A_{j}\right) e^{-\beta t}
$$

It follows that

$$
\frac{A_{f}-A_{1}}{A_{f}-A_{2}}=\frac{e^{-\beta t_{1}}}{e^{-\beta t_{2}}} .
$$

If $t_{2}-t_{1}=\Delta t$, then,

$$
\frac{A_{f}-A_{1}}{A_{f}-A_{2}}=e^{B \Delta t}
$$

or

$$
A_{f}=\frac{A_{1}-A_{2} e^{\beta \Delta t}}{1-e^{\beta \Delta t}} \text {. }
$$

For comparison purposes it is often informative to plot the area the drop will occupy when its growth is $90 \%$ complete versus the time that the drop takes to reach this area. This is done by setting

$$
A=A_{i}+0.9\left(A_{f}-A_{i}\right)
$$

substituting this expression into Equation (1) and solving for t. Then

$$
t_{90 \%}=\frac{\ln (0.1)}{\beta}
$$




\section{Instrumentation}

An instrument has been developed to perform the drop contact measurements using electro-optic techniques. The instrument has been named SWAMI (Surface Wetting Area Measurement Instrument). It uses an optical shadowing technique in conjunction with a two-dimensional CCD array and additional processing electronics to produce a numeric display which is proportional to the area wetted. A block diagram of the measurement apparatus is shown in Figure 1. Photographs of the actual instrument and typical video display are shown in Figure 2 and Figure 3.

The instrument shown actually measures the relative cross-sectional area of any solid or liquid material placed on the transparent sample substrate to be wetted. Transparent liquid drops cast a shadow which is similar to that of an opaque object by virtue of their lens-like behavior. The instrument can be calibrated for absolute area measurements by placing opaque reference areas in the beam. The overall area measurement accuracy of the apparatus in the configuration shown is $\pm 2 \%$. Further information on the characterization of the instrument and the design of the electronic interface will be forthcoming.

Using this apparatus, an investigator may rapidly obtain precise contact area information at predetermined time intervals. It should be noted, however, that by virtue of the shadowing technique used, the area measured is the maximum cross-sectional area of the drop and therefore is not representative of the contact area for substances which do not result in contact angles greater than $90^{\circ}$. This 1 imitation does not affect the results for the materials used in this study.

Preliminary Wetting Investigations on Glass

As noted previously, the actual wetting characteristics of a solid surface by a liquid depend on the surface chemistry of both the liquid and the solid to which it is applied. Therefore, the selection of reference substrate materials for the wetting evaluations of various cleaning agents 


\section{SWAMI}

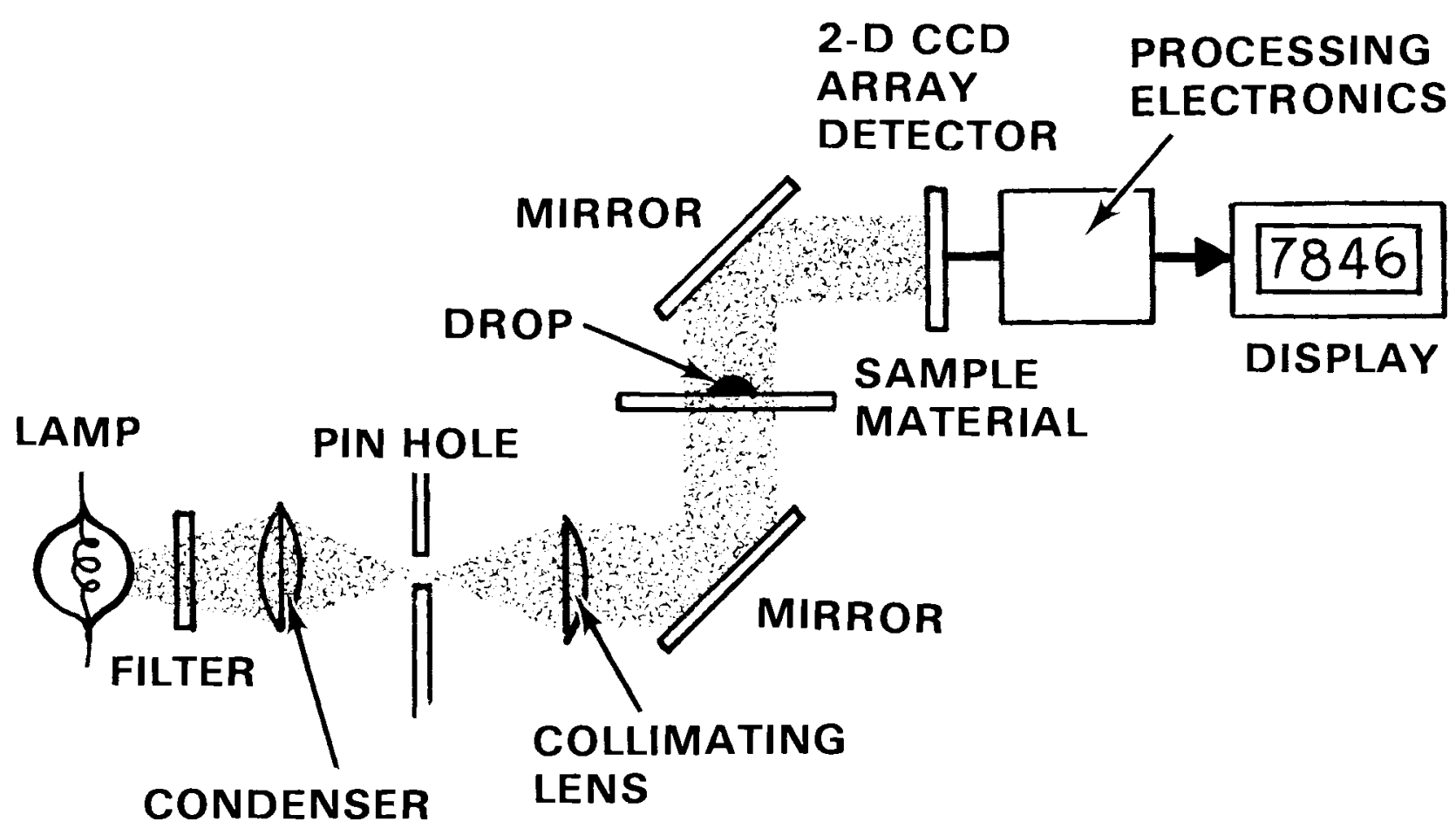

FIGURE 1. Block Diagram of Surface Wetting Area Measurement Instrument 


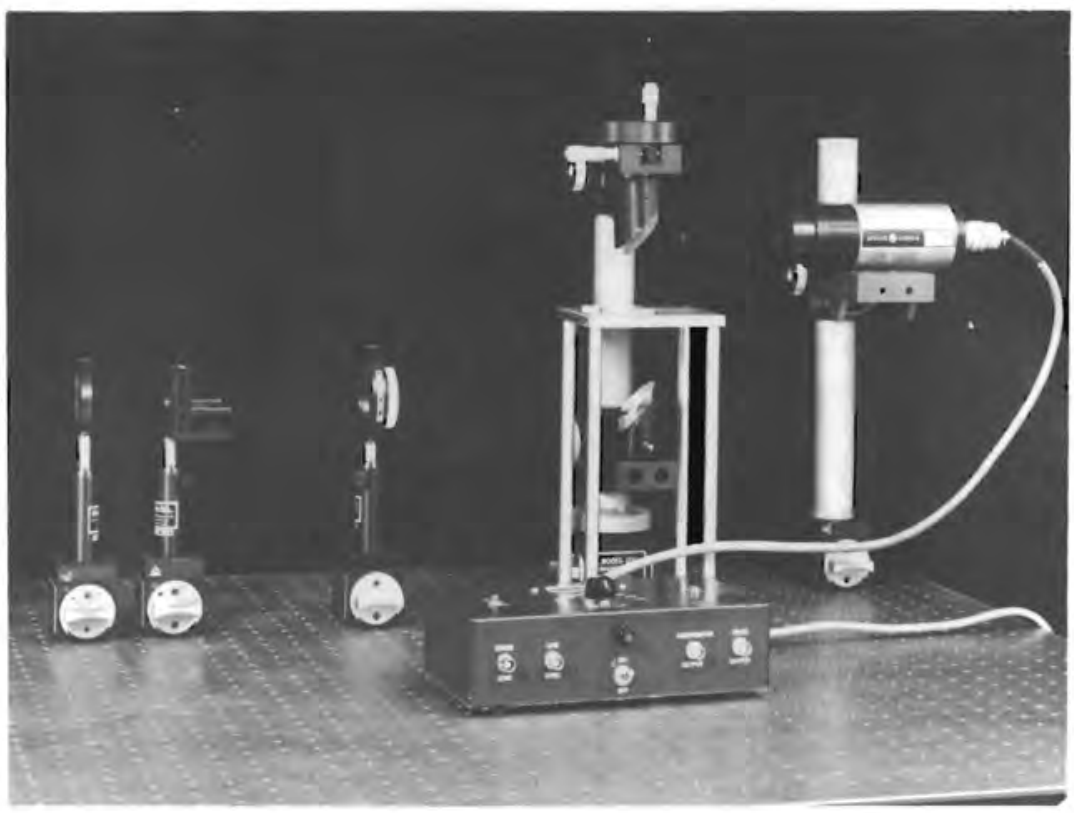

FIGURE 2. Optical Configuration for SWAMI. The light enters from the left of the photograph. The transparent substrates to be wetted are placed on the platform between the two mirrors of the perisccpe. The image of the shadow cast by the drop is projected onto the two-dimensional array detector shown at the right. The processing electronics are contained in the box in the foreground.

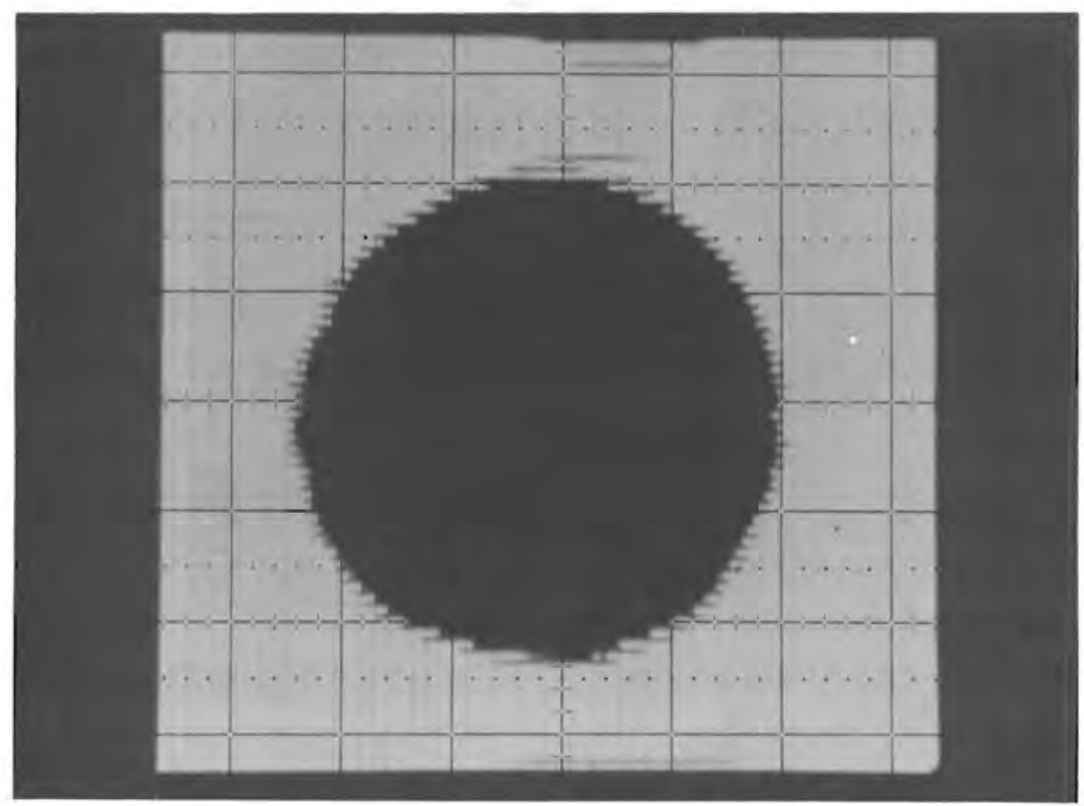

FIGURE 3. Typical Video Image of a Fairly Symmetrical Drop from the Array Detector, as Seen on a CRT Monitor 
can influence the outcome of the tests significantly. In order the determine the extent to which surface variability affects the results of the wetting studies, several glass samples produced by different commercial processing techniques were used as substrates for the preliminary measurements.

The measurements were performed by placing fixed volume drops on the glass substrate surfaces and measuring the contact area using SWAMI. The distilled water drops were dispensed in $5 \mu 1$ quantities using a metering pipette with a volumetric accuracy of $\pm 1 \%$.

Since water drops do not increase in size appreciably with time, only one measurement of each drop was necessary. A number of drops (5-10) were placed on each substrate to assure an adequate statistical sample.

At the onset of the study it was found that the results depended upon the preparation of the substrate surface prior to the actual evaluation. The method of cleaning the substrate significantly influenced the results.

A number of cleaning techniques were used which led to large deviations in the contact area for a given substrate. These techniques included cleaning with various commercial detergents and ultrasonic cleaning in a number of different solvents. In all cases the commercial detergents proved unsatisfactory, yielding highly scattered data. It was felt that the scatter may have been caused by residue left on the surface. Ultrasonic cleaning was discontinued after a review of the literature revealed that significant disruption of the surface was possible with glass substrates.

One technique that provided relatively consistent results was used for the remainder of the study on glasses. It entailed first gently wiping the substrate surface with a clean, lint-free cloth dipped in methanol. This was then followed by rinsing with distilled water and immediately blowing dry with freon gas. The substrates were then allowed to stand in a clean atmosphere for a minimum of 16 hours. Insufficient or accelerated drying led to consistently excessive wetting areas.

Once the samples were prepared, it was necessary to attach spacers on the surface to prevent contact with foreign surfaces. It was found that 
even casual contact with the aluminum support platform in the SWAMI would cause noticeable deviations in the results.

Glass surfaces produced by three different manufacturing processes were evaluated in the initial phase of the study. The substrates included annealed float, drawn and fusion glasses. Float glass is manufactured by floating the molten glass onto a bed of liquid tin and drawing off the sheet. Drawn glass is formed by drawing the sheet directly from the melt. Fusion glass is produced by overflowing a trough of molten glass to form a gr vity-drawn sheet. One might expect to see significant differences between the two surfaces of the float glass due to the infusion of tin and formation of tin oxides on the floated surface. These differences should not be present in the glasses manufactured by the other two processes.

The results of the study are shown in Tables 1 through 3 . Each side of the samples was labeled for identification. For the fusion and drawn glass, the identifications were arbitrary. The tin bath side of the float glass was identified using ultraviolet fluorescence and labeled " $A$ " in all cases. The mean area shown is a relative number based on the total unilluminated pixels on the detector array and is proportional to the actual contact area of the drop. The standard deviation of the five to ten sample average is also indicated. Two parameters of the standard t-test are also shown. Details of the test are discussed in Appendix B. "S" is the standard error of the difference between the two means, and " $t$ " is defined as the ratio of the difference between the sample means to the standard error of the difference. The conclusion column indicates whether the two measurements are the same (S) or different (D), based on the observed deviations in the measurements. The percent difference in the means is also indicated for completeness.

The tables indicate that there is indeed a significant difference between the two sides of the float glass. The side of the glass which was in contact with the molten tin during processing does not wet as well as the atmospheric side in all cases, as shown in Table 1. Both sides of the drawn glass are statistically identical for the limited number of samples studied, as shown in Table 2. 
TABLE 1. Wetting of Float Glass*

\begin{tabular}{|c|c|c|c|c|c|c|c|}
\hline $\begin{array}{c}\text { Sample } \\
\text { No. } \\
\end{array}$ & Side & $\begin{array}{l}\text { Mean } \\
\text { Area }\end{array}$ & $\begin{array}{l}\text { Std. } \\
\text { Dev. }\end{array}$ & $s$ & $t$ & Conc. & $\begin{array}{l}\% \text { Diff. } \\
\text { in Means }\end{array}$ \\
\hline \multirow[t]{2}{*}{51} & A & 1580 & 45 & 107.3 & 7.0 & D & 38.6 \\
\hline & B & 2337 & 300 & & & & \\
\hline \multirow[t]{2}{*}{52} & A & 2142 & 130 & 52 & 6.0 & D & 13.54 \\
\hline & B & 2453 & 207 & & & & \\
\hline \multirow[t]{2}{*}{53} & A & 1665 & 155 & 66.7 & 13.6 & D & 42.8 \\
\hline & B & 2571 & 266 & & & & \\
\hline \multirow[t]{2}{*}{66} & A & 1843 & 168 & 120.6 & 3.5 & D & 20.7 \\
\hline & B & 2268 & 301 & & & & \\
\hline \multirow[t]{2}{*}{67} & A & 1822 & 171 & 102.9 & 4.9 & D & 26.8 \\
\hline & B & 2385 & 235 & & & & \\
\hline \multirow[t]{2}{*}{68} & $A$ & 1839 & 248 & 129.8 & 5.4 & $D$ & 32.0 \\
\hline & B & 2541 & 271 & & & & \\
\hline \multirow[t]{2}{*}{57} & A & 1811 & 194 & 138.8 & 16.0 & $D$ & 76.0 \\
\hline & B & 4032 & 341 & & & & \\
\hline \multirow[t]{2}{*}{58} & A & 2055 & 351 & 148.7 & 8.35 & D & 46.4 \\
\hline & B & 3297 & 233 & & & & \\
\hline \multirow[t]{2}{*}{59} & A & 1822 & 85 & 123.2 & 9.4 & D & 48.4 \\
\hline & B & 2985 & 360 & & & & \\
\hline
\end{tabular}


TABLE 2. Wetting of Drawn Glass

\begin{tabular}{|c|c|c|c|c|c|c|c|}
\hline $\begin{array}{c}\text { Sample } \\
\text { No. }\end{array}$ & Side & $\begin{array}{l}\text { Mean } \\
\text { Area } \\
\end{array}$ & $\begin{array}{l}\text { Std. } \\
\text { Dev. }\end{array}$ & $\mathrm{s}$ & $t$ & Conc. & $\begin{array}{l}\% \text { Diff. } \\
\text { in Means }\end{array}$ \\
\hline \multirow[t]{2}{*}{54} & A & 1371 & 70 & 47.0 & 1.91 & $S$ & 6.8 \\
\hline & B & 1281 & 115 & & & & \\
\hline \multirow[t]{2}{*}{55} & A & 1759 & 140 & 55.2 & 1.76 & $S$ & 5.7 \\
\hline & B & 1662 & 71 & & & & \\
\hline \multirow[t]{2}{*}{56} & A & 1606 & 141 & 57.0 & 0.03 & $S$ & 0.12 \\
\hline & B & 1608 & 57 & & & & \\
\hline
\end{tabular}


TABLE 3. Wetting of Fusion Glass

\begin{tabular}{|c|c|c|c|c|c|c|c|}
\hline $\begin{array}{c}\text { Sample } \\
\text { No. } \\
\end{array}$ & Side & $\begin{array}{l}\text { Mean } \\
\text { Area } \\
\end{array}$ & $\begin{array}{l}\text { Std. } \\
\text { Dev. }\end{array}$ & $s$ & $t$ & Conc. & $\begin{array}{l}\% \text { Diff. } \\
\text { in Means }\end{array}$ \\
\hline \multirow[t]{2}{*}{61} & A & 1665 & 169 & 83.7 & 6.38 & $D$ & 27.6 \\
\hline & B & 2199 & 186 & & & & \\
\hline \multirow[t]{2}{*}{62} & A & 2437 & 290 & 113.9 & 4.86 & $D$ & 28.3 \\
\hline & B & 1833 & 203 & & & & \\
\hline \multirow[t]{2}{*}{69} & A & 2143 & 96 & 54 & 2.37 & D & 6.2 \\
\hline & B & 2015 & 113 & & & & \\
\hline \multirow[t]{2}{*}{70} & A & 2060 & 115 & 107.9 & 0.705 & $S$ & 3.8 \\
\hline & B & 1984 & 304 & & & & \\
\hline \multirow[t]{2}{*}{71} & A & 2100 & 215 & 89.2 & 3.34 & D & 15.3 \\
\hline & B & 1802 & 140 & & & & \\
\hline \multirow[t]{2}{*}{63} & A & 1966 & 78 & 48.5 & 0.165 & $S$ & 0.41 \\
\hline & B & 1974 & 113 & & & & \\
\hline \multirow[t]{2}{*}{64} & A & 2167 & 131 & 49.5 & 3.65 & D & 8.72 \\
\hline & B & 1986 & 49 & & & & \\
\hline \multirow[t]{2}{*}{65} & A & 2079 & 114 & 47.4 & 1.27 & $S$ & 2.9 \\
\hline & B & 2019 & 20 & & & & \\
\hline \multirow[t]{2}{*}{153} & A & 2200 & 193 & 67.6 & 3.71 & D & 10.8 \\
\hline & B & 2451 & 61 & & & & \\
\hline \multirow[t]{2}{*}{154} & A & 2125 & 60 & 38.7 & 8.76 & D & 15.0 \\
\hline & B & 2469 & 94 & & & & \\
\hline \multirow[t]{2}{*}{155} & A & 2331 & 62 & 32.7 & 3.21 & D & 4.41 \\
\hline & B & 2436 & 76 & & & & \\
\hline \multirow[t]{2}{*}{156} & A & 2419 & 76 & 30.3 & 0.5 & $S$ & 0.62 \\
\hline & B & 2404 & 5 & & & & \\
\hline \multirow[t]{2}{*}{157} & A & 2498 & 46 & 30.5 & 1.15 & $S$ & 1.41 \\
\hline & $B$ & 2463 & 79 & & & & \\
\hline \multirow[t]{2}{*}{158} & A & 2446 & 82 & 31.3 & 0.48 & $S$ & 0.61 \\
\hline & $B$ & 2461 & 46 & & & & \\
\hline
\end{tabular}


The results on fusion glass were not as conclusive as the results on the other two glasses, as shown in Table 3 . The t-test shows about half of the samples were statistically the same and half were different. No known differences in the manufacturing process would account for the observed results. However, local variations in the surface condition of the glass may be a contributing factor.

It should be noted that the magnification factors in the samples with numbers below 71 and above 153 were slightly different due to a change in the optical configuration of the SWAMI. Thus, the mean area numbers differ for the same drop contact area. However, this does not alter the conclusions discussed previously.

It can be concluded from the above tests that the results of wetting studies will be significantly affected by subtle changes in the surface chemistry and preparation of the substrate. It is therefore important to use identically prepared substrates for the wetting evaluation of the cleaning agents.

Cleaners on G1ass Substrates

Thirty-one cleaners were tested for their ability to wet identically prepared glass substrates. The substrates were prepared as discussed previously and allowed to dry for a minimum of 36 hours. The cleaning agents were prepared as directed by the manufacturer. Measurements of contact area versus time were made at 15 second time intervals using the SWAMI.

Nine 3- $\mu 1$ drops of the cleaning agent were placed on the surface of the glass for each sampling. From the surface area measurement of these nine drops, the obvious outliers in the data were discarded. If more than two of the nine drops were outliers, the sampling was repeated. If no outliers were present, the high and low values of each sampling were discarded. The remaining seven drops of each sampling were averaged and the standard deviation of the measurement calculated. Samplings with exceptionally large $(>20 \%)$ standard deviations were repeated.

In most cases the growth of the drop followed an exponential function, as discussed in the Introduction. The average growth curves for the cleaners 
tested are shown in Figures 4 and 5. The actual drop area (in square inches) can be roughly approximated by multiplying the relative area numbers in the figures by $10^{-5}$. The magnitude of the experimental error bars associated with each curve vary greatly. They range from $\pm 1 \%$ to $+20 \%$ of the relative drop area, depending upon the cleaner tested.

The curves should be compared with some degree of caution. The absolute magnitude of these curves depends greatly on the substrate preparation. Substrates that were dried for significantly less than 36 hours consistently led to larger values for the relative drop areas. The substrates dried for longer time periods yielded results comparable to those shown in the figures. In both cases the shape of the curves was similar.

The final area of the $\operatorname{drop}\left(A_{f}\right)$ and the time required for the drop to reach $90 \%$ of its final area $\left(t_{90 \%}\right)$ were calculated for each series of measurements as discussed previously. The results of these calculations are given in Table 4 .

Interpretation of the results is straightforward. Cleaners numbered $88,8,91 \mathrm{~A}$ and 18 started to evaporate before an equilibrium value for the contact area was reached. Therefore, the largest area attained was used as $A_{f}$. Cleaner No. 57B started evaporating immediately; therefore, the contact area at 15 seconds was used for $A_{f}$.

Figure 6 is a scatter diagram of the calculated data from Table 4. From this diagram it is possible to select a cleaner that would be most effective for a given cleaning strategy. If, for example, a cleaner that wets well in less than 15 seconds is desirable, then a logical choice would be No. 57B. If, on the other hand, the cleaning strategy would allow a relatively long time period to assure the best wetting, then cleaner No. 59 would be a logical choice.

\section{Cleaners on Plastic Substrates}

Wetting studies were also performed on a small group of commonly used plastics. Substrates included a polycarbonate, a polyvinylfluoride, an acrylic, and a polyester. The cleaning agents that were used in the study are listed with their manufacturers or distributors in Appendix B. Again, 


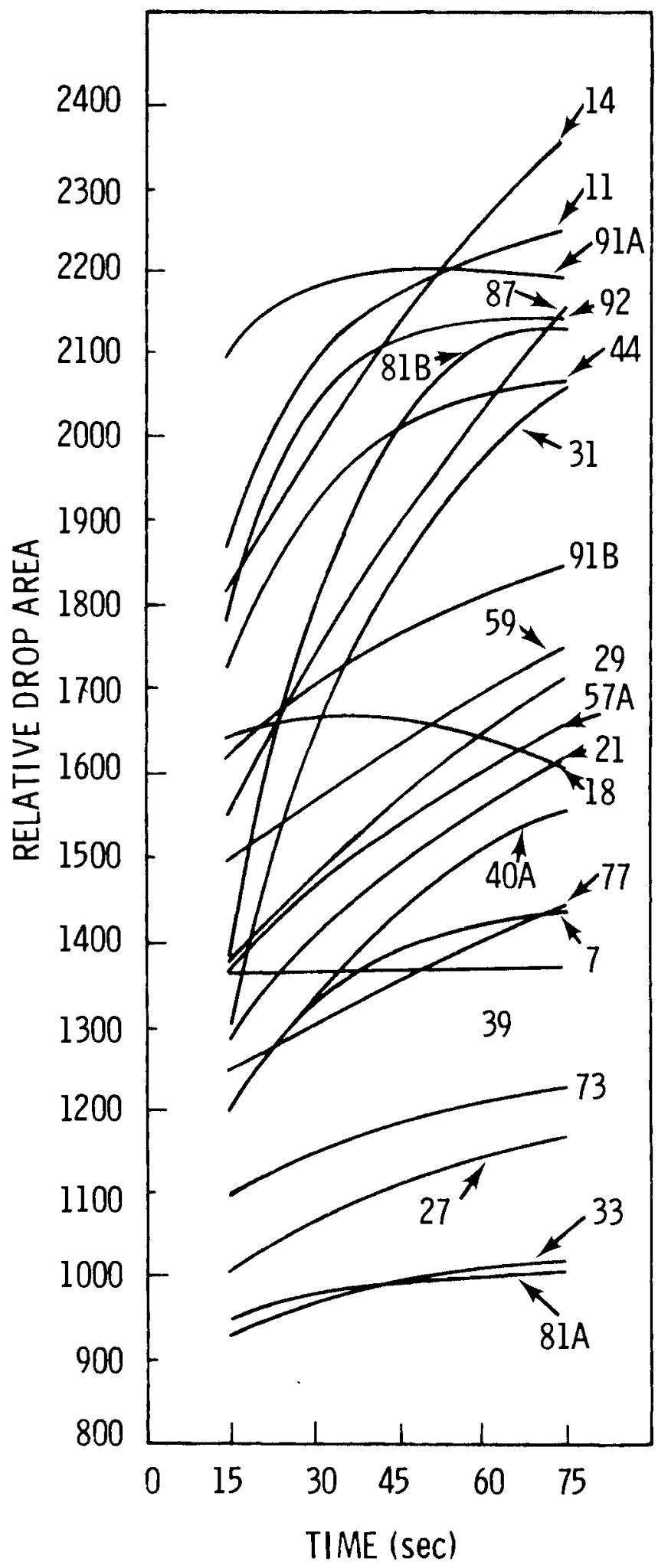

FIGURE 4. Wetting Characteristics for Selected Cleaners on Glass 


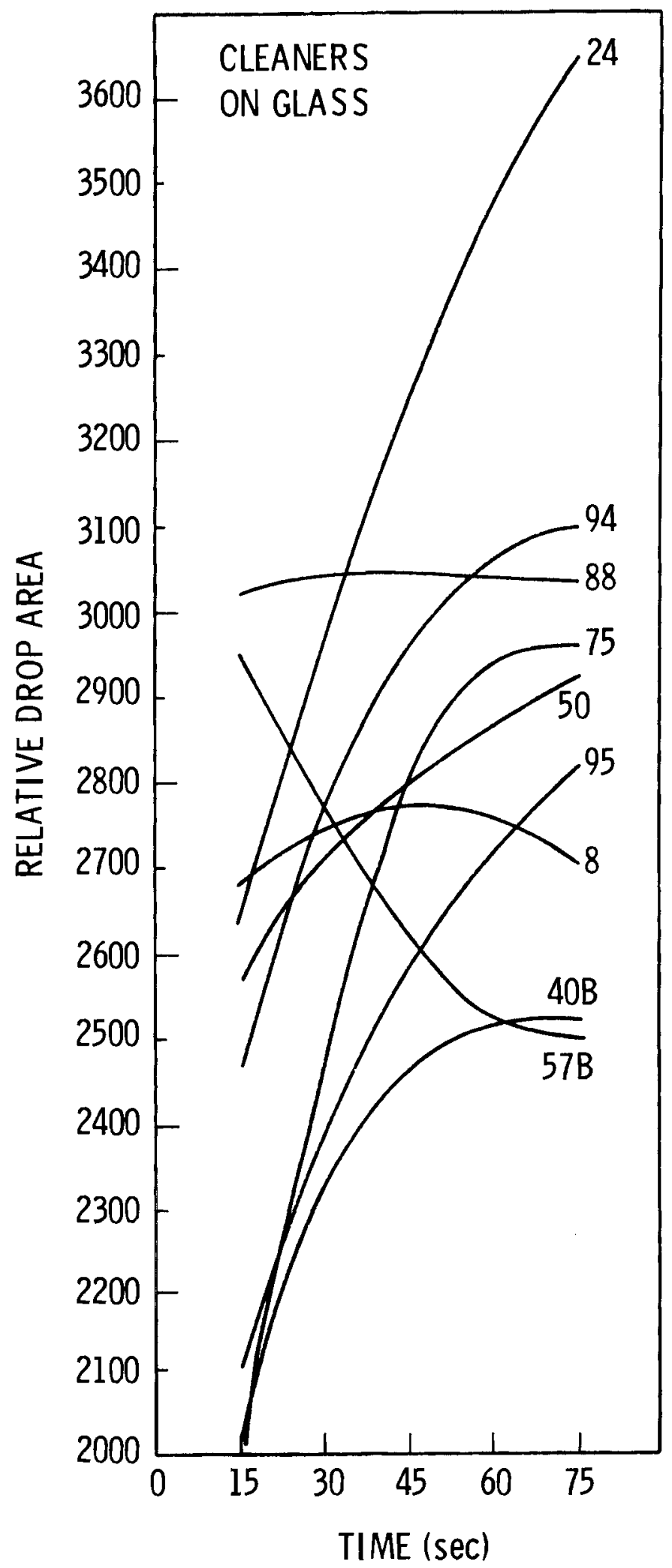

FIGURE 5. Wetting Characteristics for Selected Cleaners on Glass 
TABLE 4. Relative Wetting Data for Selected Cleaning Agents on Glass

Cleaner Code

7

8

11

14

18

21

24

28

29

31

33

39

$40 A$

$40 \mathrm{~B}$

44

50

$57 \mathrm{~A}$

$57 \mathrm{~B}$

59

73

75

77

$81 \mathrm{~A}$

$81 B$

87

88

$91 \mathrm{~A}$

91B

92

94

95
Af

1453

2771

2257

4235

1665

1784

4517

1231

2687

2197

1055

1371

1701

2535

2081

3009

1850

$>2945$

5684

1255

3055

1974

1019

2183

2963

3210

2186

1945

2141

3175

3011 $\mathrm{t}_{90 \%}$

51.3

045.0

42.9

573.3

039.0

126.7

180.5

109.5

464.1

73.3

114.0

49.8

112.6

38.6

47.5

84.6

149.5

$<15.0$

2210.0

83.3

58.5

439.5

64.9

52.2

253.3

042.0

15.6

119.5

29.5

62.5

90.7 


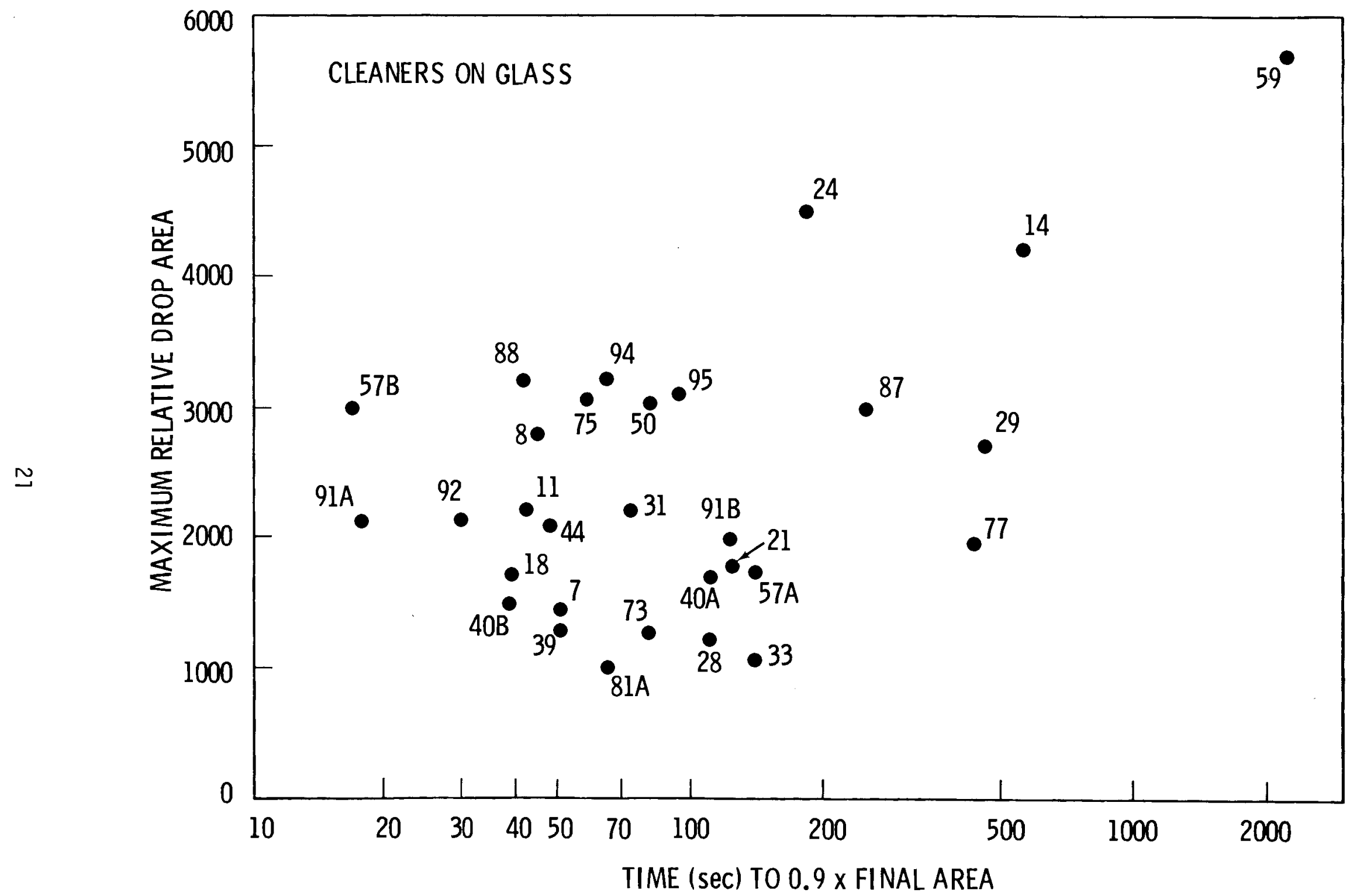

FIGURE 6. Scatter Diagram of Wetting Parameters for Selected Cleaners on Glass 
no attempt was made to do an exhaustive study but only to screen selected commercially available agents recommended by the manufacturers.

The techniques used to perform the studies were nearly identical to those used in the section on glass cleaners, the only exception being in the pre-cleaning process. Since the surface of the plastic materials is considerably softer than glass, a cotton swab was substituted for the lintfree rag. Also, because some of the plastics are sensitive to alcohol, a detergent was substituted, followed by a lengthy rinse in deionized water.

The same caution should be applied in interpreting the wetting studies on plastics as was applied to the studies on glass. Large variability in the samplings is possible with small changes in the surface preparation. Substrates that were used repeatedly tended to wet better than the virgin material due to surface roughening and abrasion. Therefore, virgin material was used for the substrates whenever possible.

The wetting curves for the cleaners tested on each of the four plastic substrates are given in Figures 7-10. Tables 5-8 1ist the calculated values for the final area, $A_{f}$, and time necessary to reach $90 \%$ of that area, $t_{90 \%}$. The scatter diagrams for $A_{f}$ versus $t_{90 \%}$ are given in Figures 11-14. 


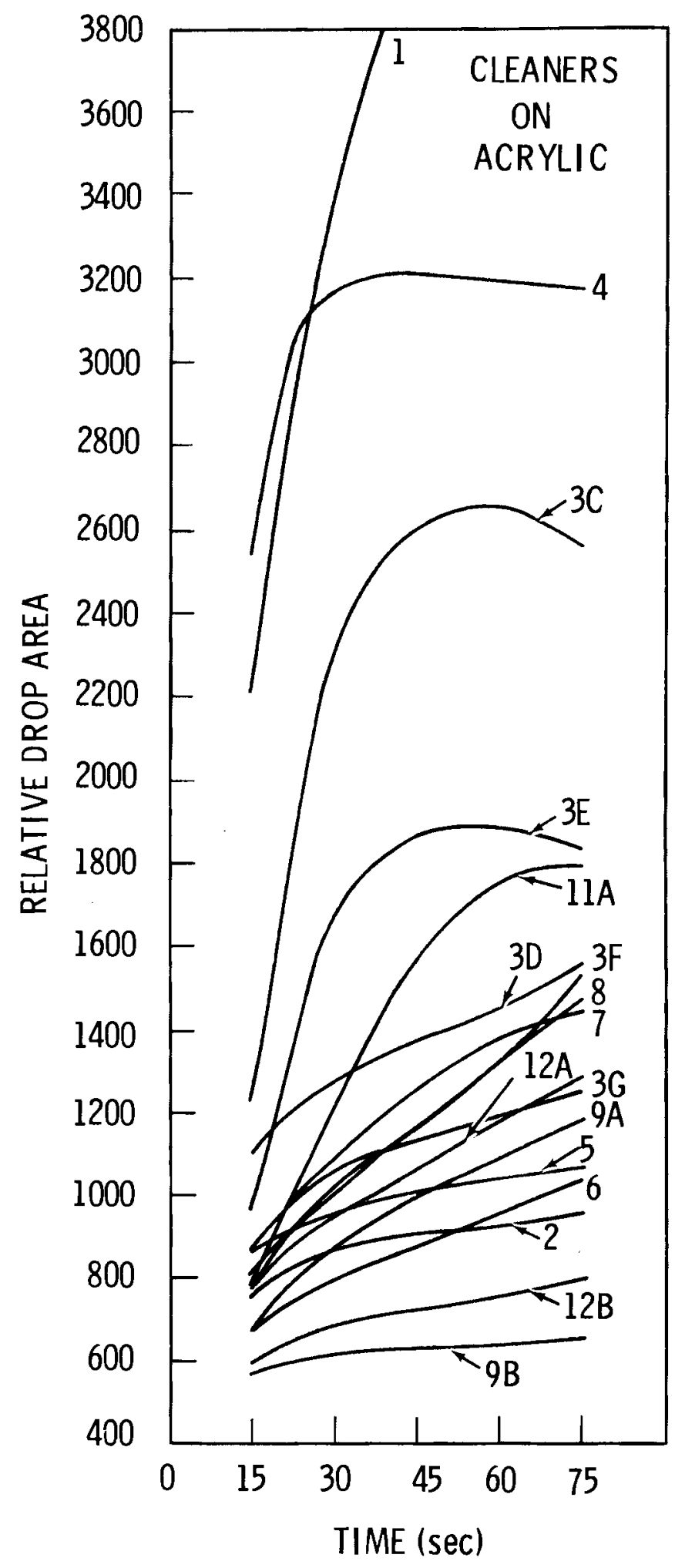

FIGURE 7. Wetting Characteristics of Selected Cleaners on Acrylic 


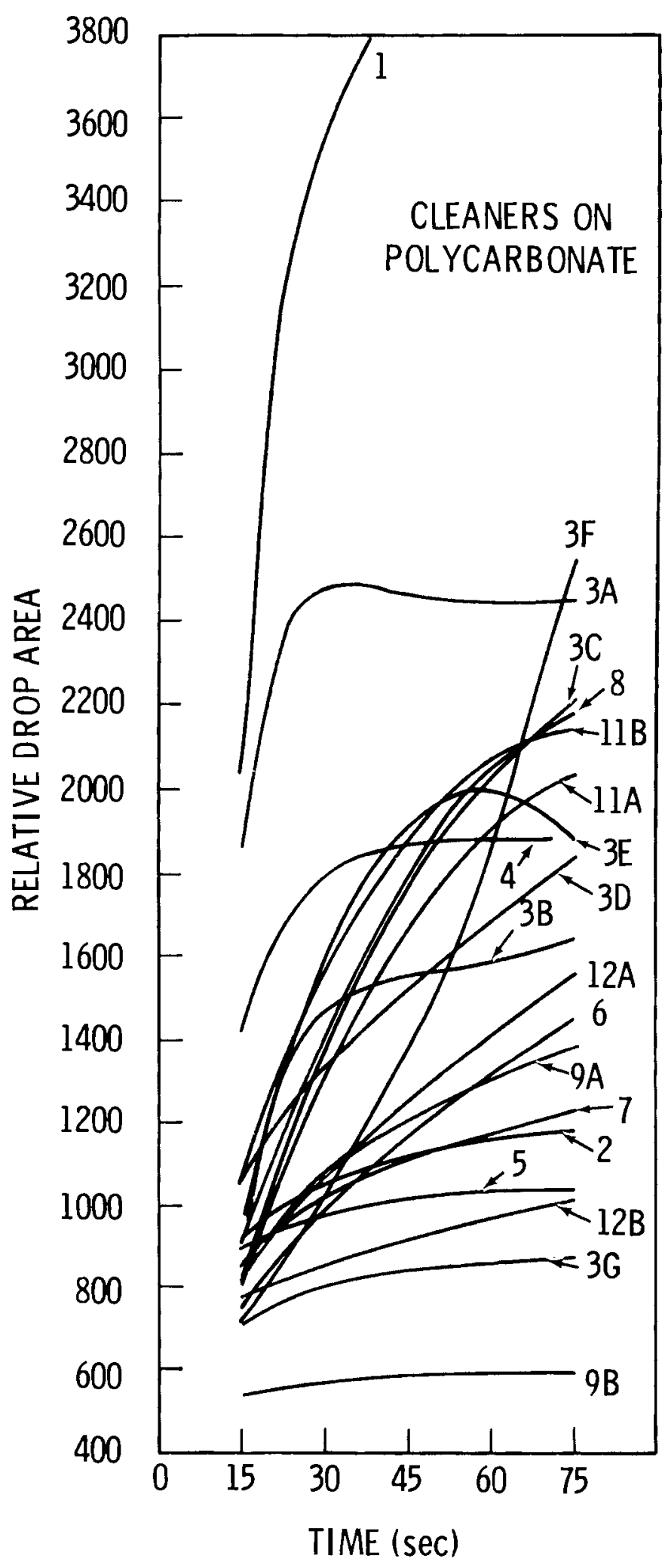

FIGURE 8. Wetting Characteristics of Selected Cleaners on Polycarbonate 


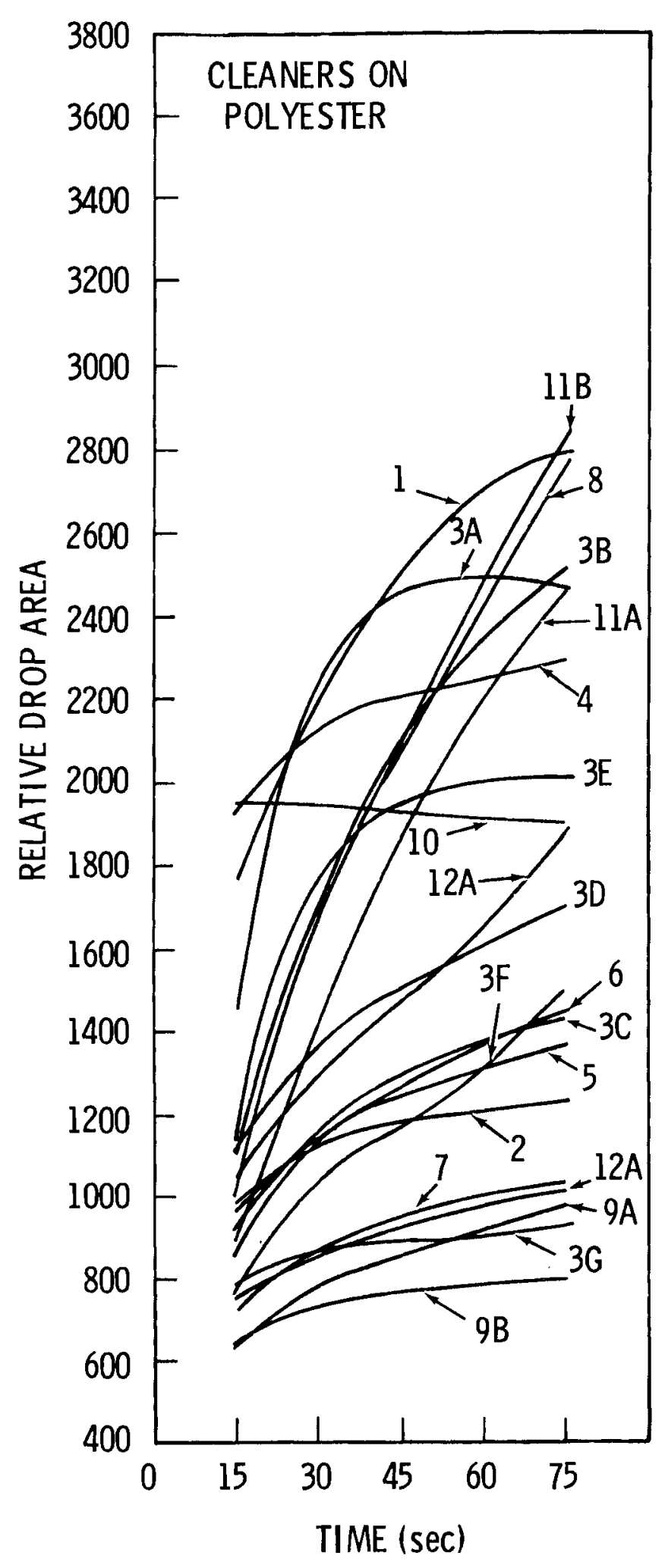

FIGURE 9. Wetting Characteristics of Selected Cleaners on Polyester 


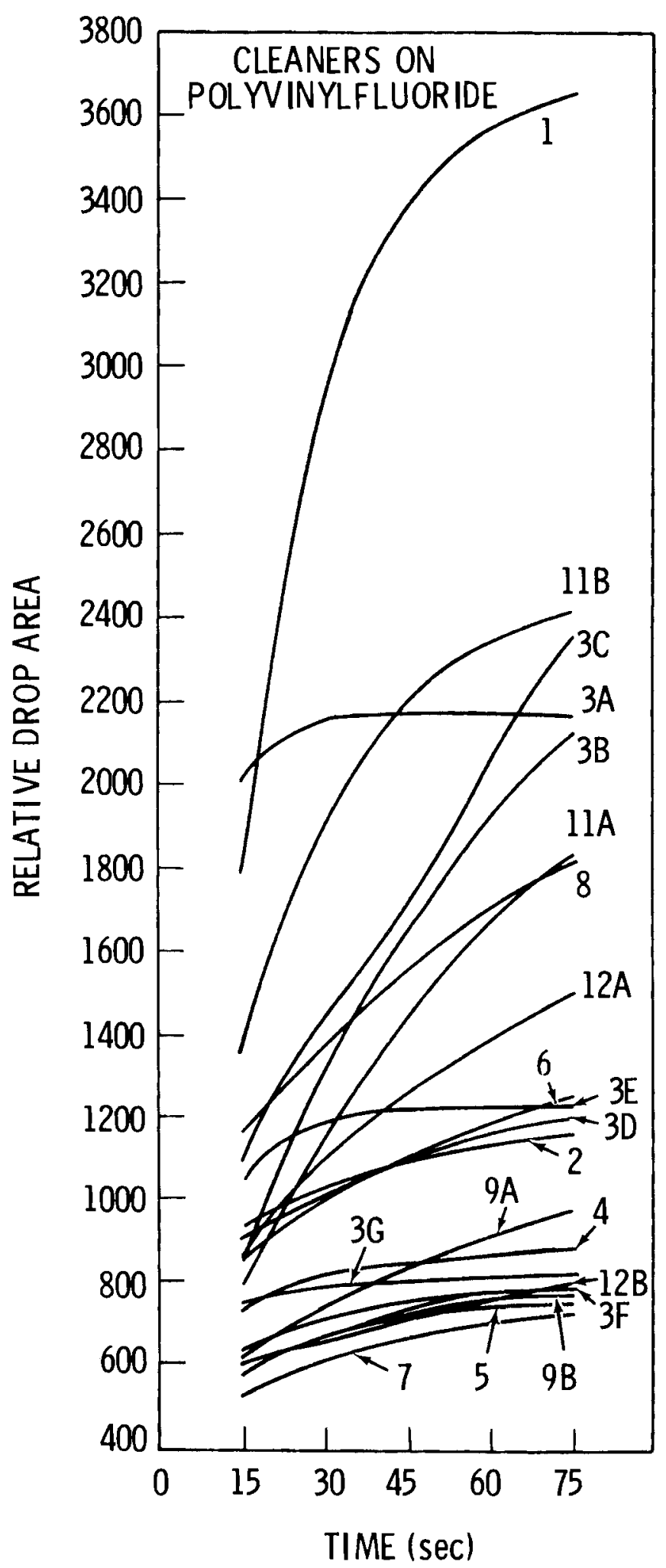

FIGURE 10. Wetting Characteristics of Selected Cleaners on Polyvinylfluoride 
TABLE 5. Relative Wetting Data for Selected Cleaning Agents on Acrylic

\begin{tabular}{crr} 
Cleaner Code & $A_{f}$ & $t_{90 \%}$ \\
\cline { 2 - 3 } 1 & 4360 & 44.6 \\
2 & 965 & 47.2 \\
$3 A$ & 2390 & 37.0 \\
$3 B$ & 2048 & 38.1 \\
$3 C$ & 2559 & 30.8 \\
$3 D$ & 1614 & 83.8 \\
$3 E$ & 1829 & 28.8 \\
$3 F$ & 1949 & 135.9 \\
$3 G$ & 1281 & 54.6 \\
4 & 3198 & 50.0 \\
5 & 1111 & 77.7 \\
6 & 1350 & 177.5 \\
7 & 1956 & 152.8 \\
8 & 2499 & 278.9 \\
$9 A$ & 1314 & 86.7 \\
$9 B$ & 657 & 47.6 \\
10 & -- & -- \\
$11 A$ & 2064 & 89.8 \\
$11 B$ & 2018 & 73.2 \\
$12 A$ & 1543 & 133.3 \\
$12 B$ & 850 & 99.7
\end{tabular}




\section{TABLE 6. Relative Wetting Data for Selected Cleaning Agents on Polycarbonate}

\begin{tabular}{|c|c|c|}
\hline Cleaner Code & $A_{f}$ & $t_{90 \%}$ \\
\hline 1 & 4141 & 33.0 \\
\hline 2 & 1210 & 52.6 \\
\hline $3 A$ & 2480 & 030 \\
\hline $3 B$ & 1642 & 28.8 \\
\hline $3 C$ & 2636 & 98.3 \\
\hline 30 & 2315 & 139.8 \\
\hline $3 E$ & 1880 & 37.4 \\
\hline $3 F$ & 1010 & 030 \\
\hline $3 G$ & 888 & 50.2 \\
\hline 4 & 1910 & 22.8 \\
\hline 5 & 1039 & 38.3 \\
\hline 6 & 2254 & 213.0 \\
\hline 7 & 1304 & 71.6 \\
\hline 8 & 2681 & 108.0 \\
\hline $9 A$ & 1492 & 72.3 \\
\hline $9 B$ & 598 & 52.3 \\
\hline 10 & -- & -- \\
\hline $11 \mathrm{~A}$ & 2485 & 104.0 \\
\hline $11 B$ & 2338 & 67.2 \\
\hline $12 \mathrm{~A}$ & 3041 & 344.0 \\
\hline $12 B$ & 1294 & 211.6 \\
\hline
\end{tabular}




\section{TABLE 7. Relative Wetting Data for Selected Cleaning Agents on Polyester}

\begin{tabular}{crr} 
Cleaner Code & $A_{f}$ & $t_{90 \%}$ \\
\cline { 2 - 3 } 1 & 3227 & 112.6 \\
2 & 1241 & 36.7 \\
3A & 2470 & 29.4 \\
3B & 2693 & 67.8 \\
3C & 4184 & 59.1 \\
3D & 1830 & 80.5 \\
3E & 2022 & 32.4 \\
$3 F$ & 1766 & 105.5 \\
3G & 941 & 50.8 \\
4 & 2304 & 44.6 \\
5 & 1390 & 43.9 \\
6 & 1701 & 129.2 \\
7 & 1103 & 76.3 \\
8 & 3473 & 112.1 \\
$9 A$ & 1064 & 84.3 \\
$9 B$ & 819 & 51.9 \\
10 & 1950 & 15.0 \\
$11 A$ & 3730 & 174.1 \\
$11 B$ & 4378 & 186.3 \\
$12 A$ & 3124 & 268.2 \\
$12 B$ & 1138 & 113.6
\end{tabular}


TABLE 8. Relative Wetting Data for Selected Cleaning Agents on Polyvinylfluoride

\begin{tabular}{ccc} 
Cleaner Code & $A_{f}$ & $t_{90 \%}$ \\
\cline { 2 - 3 } 1 & 3703 & 41.9 \\
2 & 1159 & 80.9 \\
$3 A$ & 2167 & 030 \\
$3 B$ & 2808 & 122.9 \\
$3 C$ & 1540 & 030 \\
$3 D$ & 1338 & 99.7 \\
$3 E$ & 1222 & 20.6 \\
$3 F$ & 827 & 79.7 \\
$3 G$ & 799 & 33.2 \\
4 & 892 & 50.8 \\
5 & 763 & 54.4 \\
6 & 998 & 030 \\
7 & 808 & 103.3 \\
8 & 2403 & 187.9 \\
$9 A$ & 1199 & 146.0 \\
$9 B$ & 780 & 51.7 \\
10 & -- & -- \\
$11 A$ & 2770 & 185.0 \\
$11 B$ & 2496 & 52.9 \\
$12 A$ & 1835 & 127.9 \\
$12 B$ & 981 & 210.0
\end{tabular}




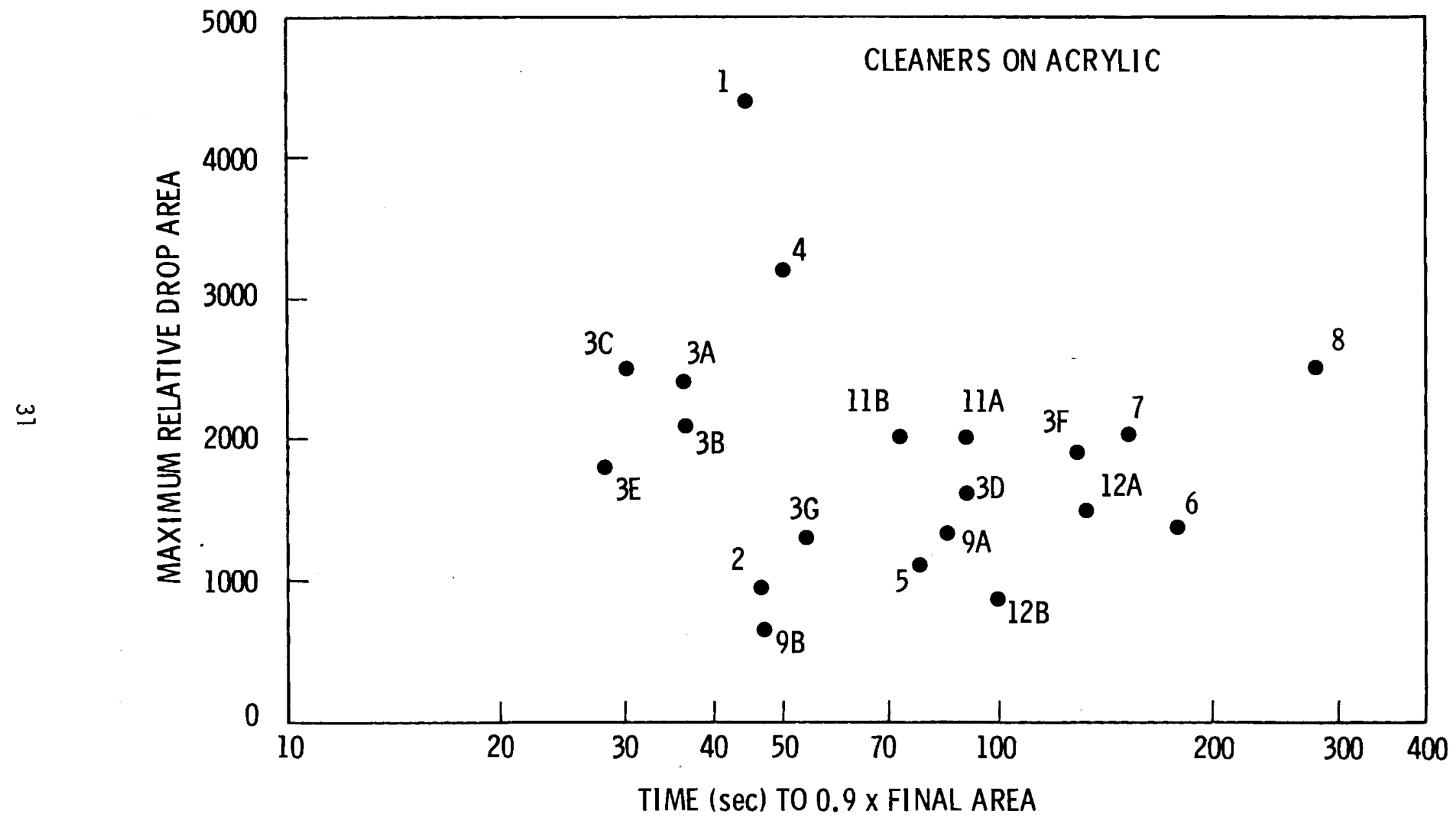

FIGURE 11. Scatter Diagram of Wetting Parameters for Selected Cleaners on Acrylic 


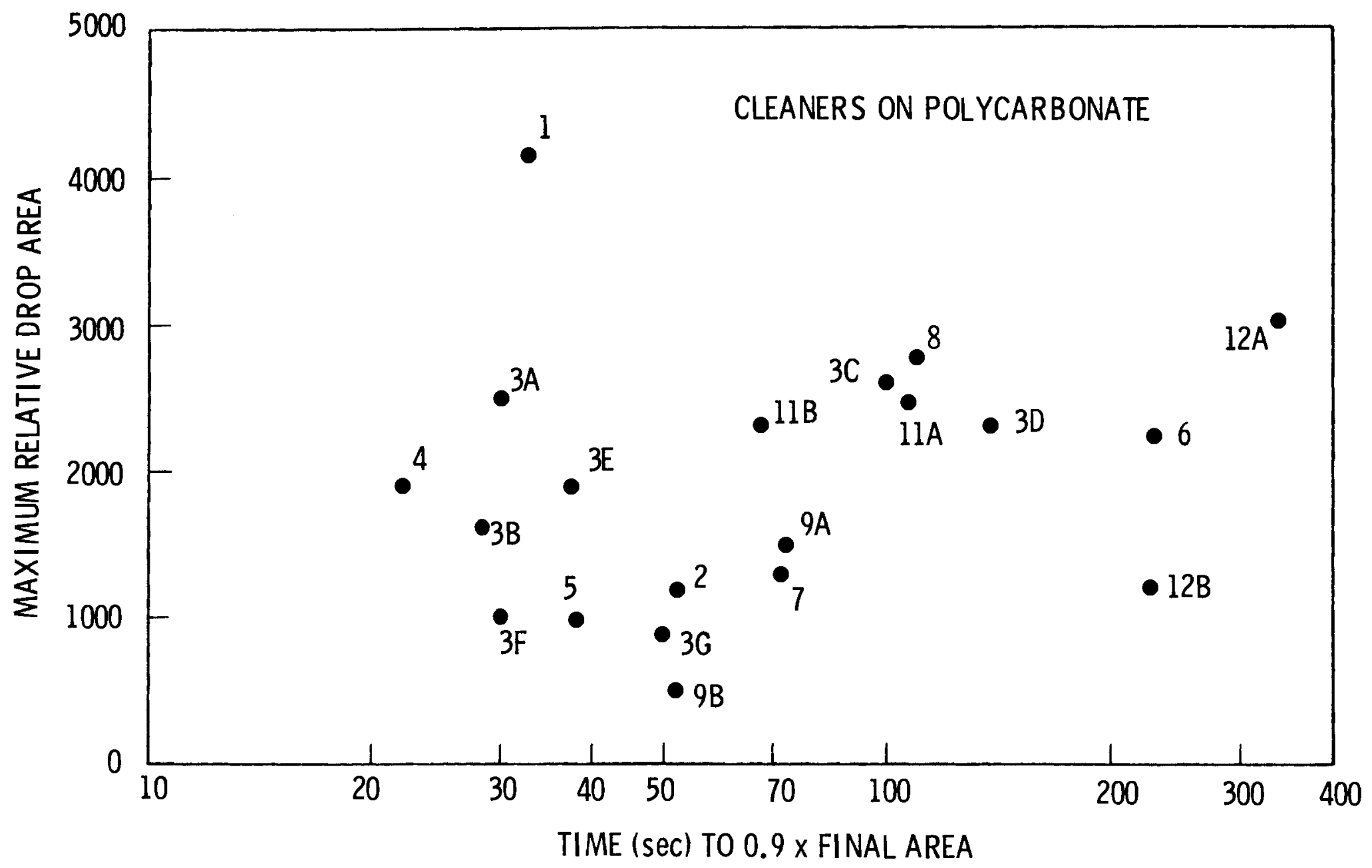

FIGURE 12. Scatter Diagram of Wetting Parameters for Selected Cleaners on Polycarbonate 


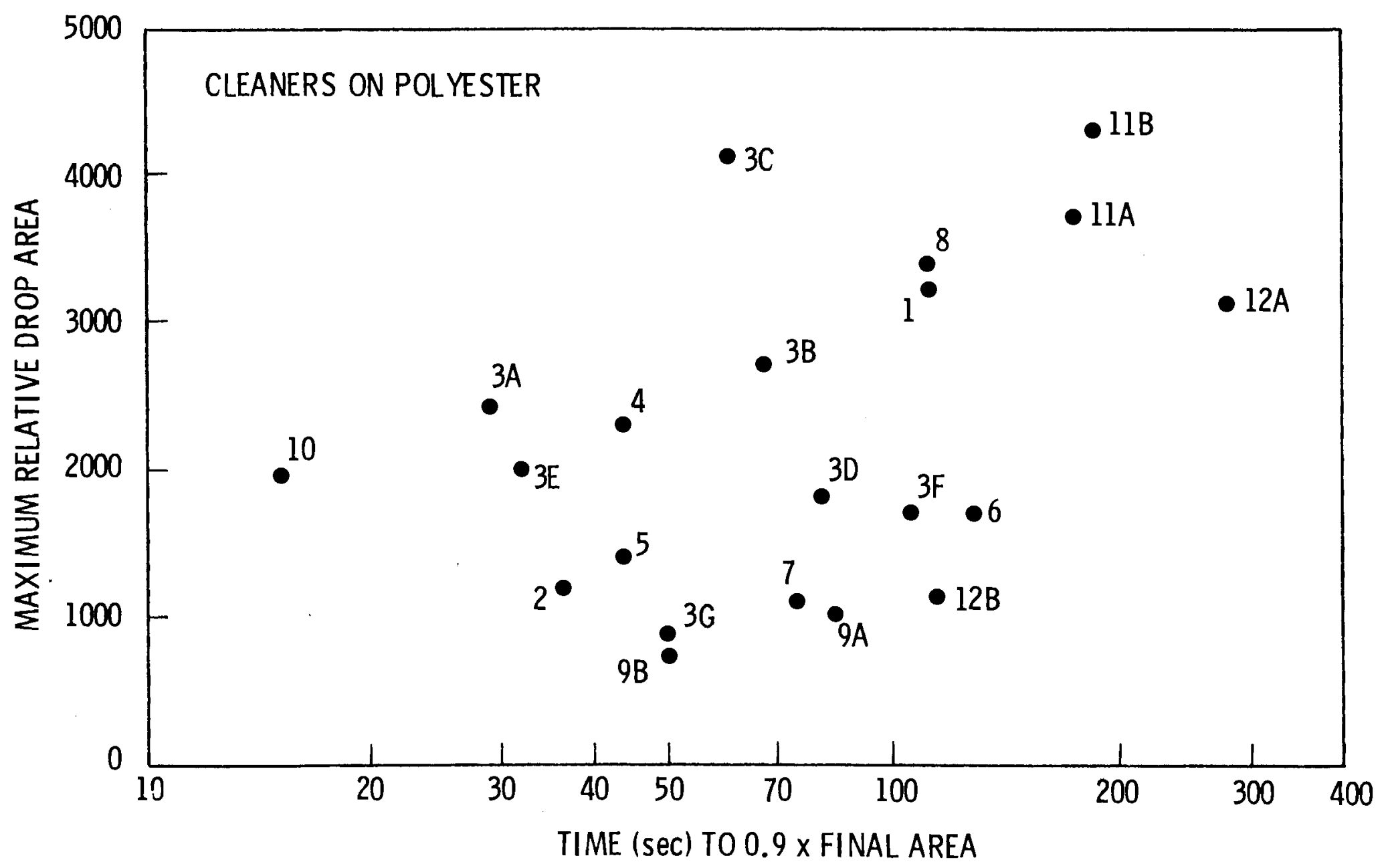

FIGURE 13. Scatter Diagram of Wetting Parameters for Selected Cleaners on Polyester 


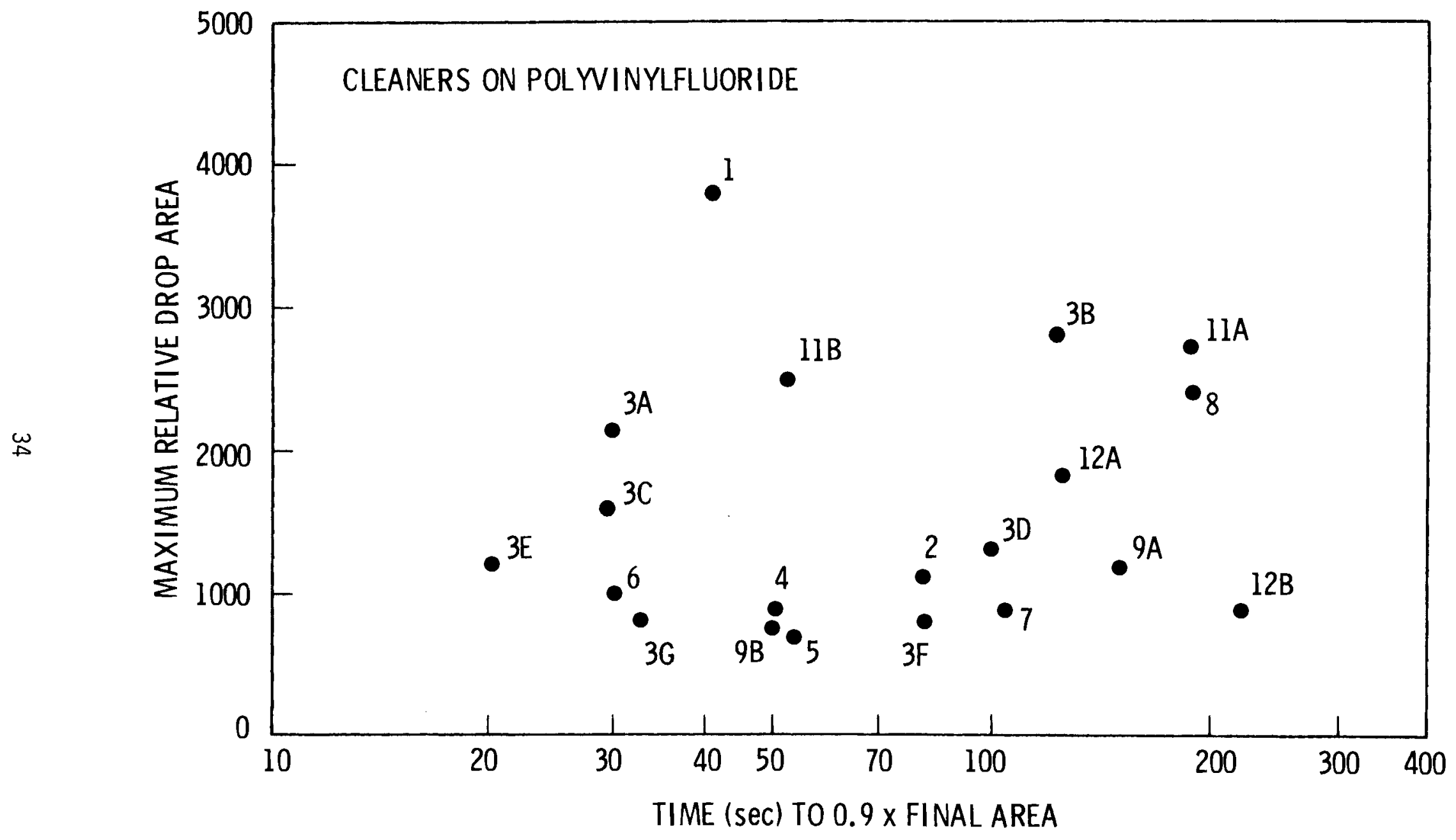

FIGURE 14. Scatter Diagram of Wetting Parameters for Selected Cleaners on Polyvinylfluoride 


\section{RESIDUE STUDIES}

\section{Background}

The deleterious effects of the cleaning agents on the substrate after repeated application are also of concern when comparing the relative merits of cleaners. Residue buildup or changes in the surface of the substrate can cause losses in the transmittance or reflectance of the optical elements in a solar installation. The loss mechanisms are primarily due to absorption or scattering at the surface of the substrate.

Prospective cleaning agents should be screened for undesirable effects on the optical substrates to which they are applied. Keeping in mind a high pressure, noncontact cleaning strategy, a simple test apparatus was constructed to evaluate the effects of repeated applications of our group of glass cleaners under semi-realistic conditions. The basic idea was to spray on, rinse, and dry off the cleaning agent from a transparent substrate a few hundred times and compare the solar transmittance before and after the process.

Instrumentation

An apparatus was deisgned and constructed to spray rinse and air dry 2 inch $\times 2$ inch samples with the cleaner of interest on a continuous basis. The device, which is shown in Figure 15, uses all glass sample holders and surroundings to eliminate the problem of residues formed by reactions with dissimilar materials. The apparatus can hold up to 13 samples on a $58 \mathrm{~cm}$ diameter rotating wheel. This wheel rotates at approximately $0.8 \mathrm{rpm}$, spraying each sample with cleaner for roughly 2.1 seconds/revolution. The rinse cycle occurs over the same period of time and in the same manner as the cleaner spray. For both cleaning and rinsing, an air brush type sprayer was used. Both sprayers are activated by $\mathrm{N}_{2}$ at approximately 30 psi. It was felt that low pressure cleaning would produce the worst case conditions for residue buildup. Each sprayer is activated by a separate microswitch to avoid overspraying onto other samples and excessive use of cleaning solutions. 


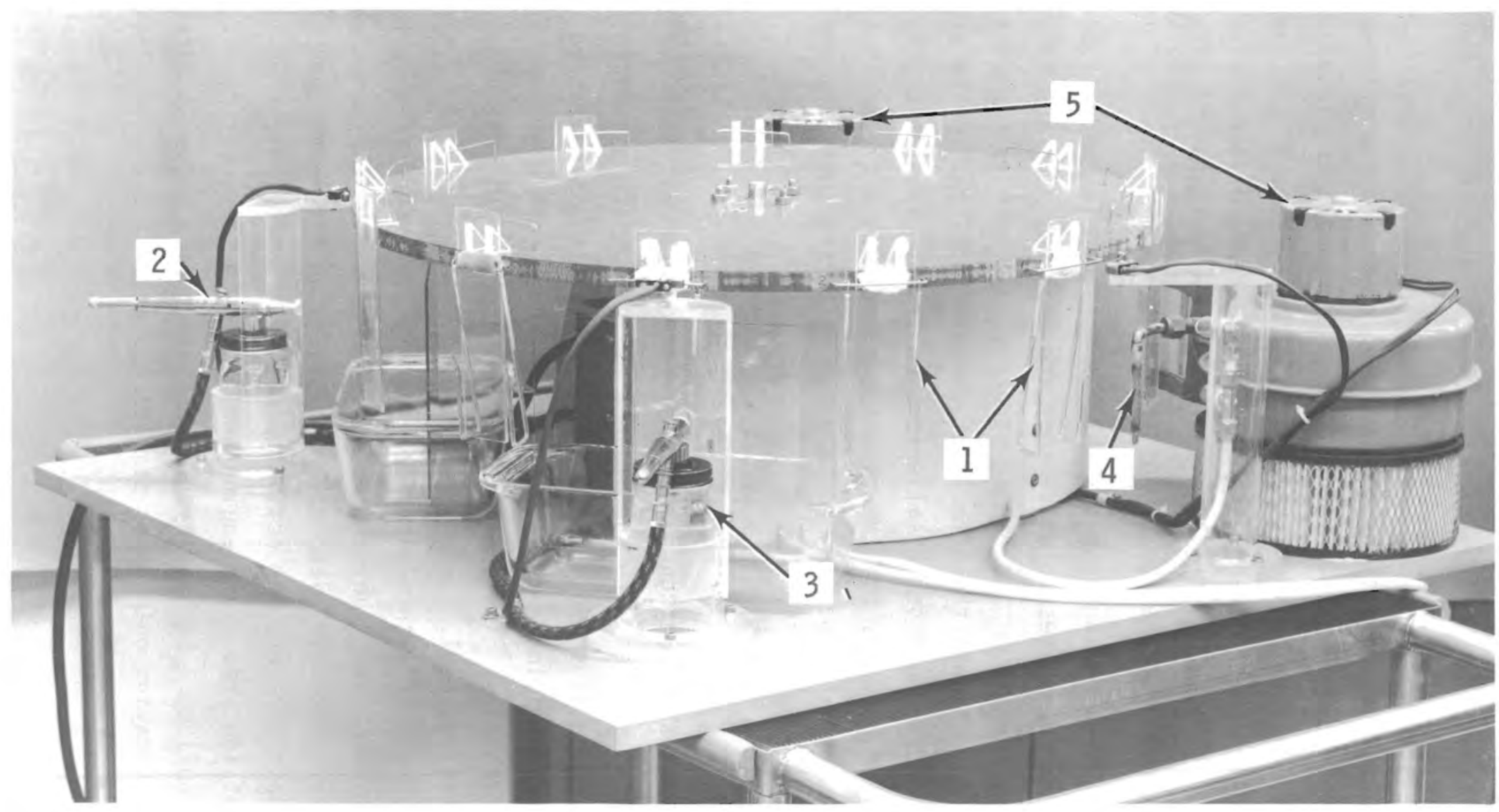

FIGURE 15. Photograph of Cleaner Residue Deposition Apparatus. Shown are: 1) the glass sample holders, 2) the airbrush liquid cleaner applicator, 3) the airbrush rinse applicator, 4) the airjet drying station, and 5) the filtered blower drying stations. 
Drying of the samples may occur in three stages. The first (optional) stage is activated by a microswitch and blows $\mathrm{N}_{2}$ at 30 psi onto the sample. This stage remove the larger droplets and sheets of rinse solution from the sample. The second and third stages of the drying process are identical and consist of two continuously running filtered blowers feeding air onto the samples at $160 \mathrm{cfm}$. The samples, after passing the drying stage, are then moved back to the spray wash stage. It should be noted that the spray wash, spray rinse and the first drying stage use $99.9 \%$ pure $\mathrm{N}_{2}$ to avoid residue buildup due to the contaminants present in most compressed air sources.

The sprayers are adjusted so that roughly the top $70 \%$ of the sample is wetted by the direct spray and the lower $30 \%$ is wetted by runoff of the accumulated cleaning or rinsing agent. This positioning was chosen to enable the investigator to determine to what extent residue buildup in preceding cycles was removed by the force of the direct spray.

\section{Residue on Glass Substrates}

Only the glass cleaners previously evaluated for their wetting characteristics were examined for their residue buildup characteristics. Fusion glass was chosen for the substrate material.

The tests reported below were run without the use of the airjet first stage dryer since worst case conditions were of primary interest. The high pressure dryer removed most of the liquid from the substrate by displacement rather than evaporation. This results in a lower amount of residue being left by the cleaning agent than if the substrate was left to dry "naturally."

The cleaners were sprayed onto the glass substrates and air-dried for 200 cycles. The substrates were then removed and measured for their solar transmittance. The cleaning agents used in the tests were prepared according to the manufacturers' specifications. Neither the cleaning agents nor the rinse fluids were recycled during the tests.

Table 9 shows the loss in solar transmittance due to the buildup of cleaner residue. This loss was obtained by comparing the solar specular 
TABLE 9. Transmittance Losses Due to Residue Buildup of Glass Cleaners After Repeated Application

\begin{tabular}{|c|c|c|}
\hline Cleaner Code & $\Delta T$ (Average) & $\Delta T$ (Worst) \\
\hline 7 & 0.002 & -- \\
\hline 8 & 0.340 & 0.406 \\
\hline 11 & 0.003 & -- \\
\hline 14 & 0.006 & 0.012 \\
\hline 18 & 0. & -- \\
\hline 21 & 0. & -- \\
\hline 24 & 0 & -- \\
\hline 28 & 0.003 & -- \\
\hline 29 & 0 & -- \\
\hline 31 & 0.002 & -- \\
\hline 33 & 0.001 & -- \\
\hline 39 & 0.001 & -- \\
\hline $40 \mathrm{~A}$ & 0.008 & 0.016 \\
\hline $40 B$ & 0. & -- \\
\hline 44 & 0.004 & -- \\
\hline 50 & 0.002 & -- \\
\hline $57 \mathrm{~A}$ & 0.002 & -- \\
\hline $57 \mathrm{~B}$ & 0.003 & -- \\
\hline 59 & 0 & -- \\
\hline 73 & 0.005 & -- \\
\hline 75 & 0.002 & -- \\
\hline 77 & 0 & -- \\
\hline $81 \mathrm{~A}$ & 0.009 & 0.035 \\
\hline $81 \mathrm{~B}$ & 0.007 & 0.035 \\
\hline 87 & 0.045 & 0.102 \\
\hline 88 & 0.001 & -- \\
\hline $91 \mathrm{~A}$ & -0.007 & -- \\
\hline $91 \mathrm{~B}$ & -0.007 & -- \\
\hline 92 & 0.003 & - \\
\hline 94 & 0.002 & -- \\
\hline
\end{tabular}


$\left(\sim 7^{\circ}\right)$ transmittance of the substrate before and after the cleaning cycles. Moon's AM 2 spectral data ${ }^{3}$ was used for the weighting.

The table shows both the average and worst case degradation observed for three substrates. The highest losses occurred in the lower $30 \%$ of the substrate where the spray was not directly incident on the surface. This implies that in many cases, the residue was prevented from reaching significant levels by the disruptive action of the direct spray.

The relative accuracy of the transmittance measurements is approximately $\pm 0.5 \%$. Therefore, changes in transmittance on the order of $1 \%$ may be within the noise of the measurement. Only six of the tested cleaners $(8,14,40 \mathrm{~A}, 81 \mathrm{~A}, 81 \mathrm{~B}$ and 87$)$ left any significant residue. Two cleaners (91A and 91B) left residues that actually increased the transmittance of the substrate slightly.

3 P. Moon, "Proposed Standard Solar Radiation Curves for Engineering Use," Journal of the Frankl in Institute 320:604, Table III, 1940. 
. 


\section{FIGURE OF MERIT}

\section{Background}

It is an interesting, although certainly speculative, exercise to construct a figure of merit for each of the cleaners in order to compare them. The formulation of a figure of merit must be sensitive to the cost and effectiveness of the cleaner, the cleaning strategy to be used, the cost of labor for application, and a large number of other variables.

The actual weighting given to the various parameters depends not only on the overall cleaning strategy, but also on the type and design of collector field. The figure of merit presented below is based on the following four assumptions.

- A heavy penalty should be paid by cleaning agents that reduce the solar transmittance of the sample. The argument can be made that in large central receiver reflector applications, the cost of adding additional heliostats to compensate for transmittance losses is proportional to $(1-\Delta T)^{\alpha}$ where $T$ is the transmission loss and $\alpha \geq 1$, depending on the size and configuration of the collector field.

- There is an optimum time in the cleaning strategy that the cleaner will be allowed to sit in order to achieve maximum wetting. A penalty should be assessed for cleaners whose optimum wetting time, $t_{90 \%}$, is significantly different from the optimum time allotted in the cleaning scheme, $t_{\text {opt }}$.

- The performance of the cleaner is directly proportional to how well it wets the surface of the material to which it is applied at the optimum time. Thus, the figure of merit should be proportional to $A_{f}\left(t=t t_{o p t}\right)$.

- The figure of merit should also be inversely proportional to the cost of the product, $K$.

Combining these factors and making some reasonable assumptions about the magnitude of $\alpha$ and $t_{\text {opt }}$, the figure of merit could be written as 


$$
M=\frac{[1-\Delta T]^{2} A_{f}(t=20)}{K} .
$$

\section{Results for Glass Cleaners}

Based on Equation (13), the results of our previous investigations and the cost data supplied in Table 10, $M$ can be calculated for the glass cleaners that were tested. The costs are for the diluted, ready-to-apply solutions. They are calculated from the manufacturer's suggested retail price for 55 gallon drums of concentrate supplied in large quantities FOB their point of origin. The values of $M$ are displayed graphically in Figure 16. Given the previous assumptions, the largest values for $M$ represent the most desirable cleaners.

Again, it should be emphasized that this figure of merit is somewhat arbitrary and should be viewed as such. The actual "best" cleaner will depend on the exact cleaning strategy that is employed. 
TABLE 10. Cleaning Solution cost and Relative Figure of Merit

\begin{tabular}{ccr} 
Cleaner Code & \multicolumn{1}{c}{$(\$ / g a l)}$. & \multicolumn{1}{c}{$M$} \\
\hline 7 & 1.96 & 636.22 \\
11 & 8.42 & 231.62 \\
14 & 175.00 & 10.57 \\
18 & 168.00 & 9.83 \\
21 & 138.00 & 9.65 \\
24 & 5.37 & 551.02 \\
28 & 0.63 & 1620.39 \\
29 & 3.50 & 402.57 \\
31 & 127.00 & 11.25 \\
33 & 1.63 & 577.37 \\
39 & 27.27 & 49.95 \\
$40 A$ & 9.70 & 127.02 \\
$40 B$ & 8.33 & 257.98 \\
44 & 12.94 & 138.38 \\
50 & 395.00 & 6.63 \\
$57 A$ & 1.28 & 1093.27 \\
$57 B$ & 21.18 & 135.44 \\
59 & 71.78 & 21.16 \\
75 & 3.51 & 314.78 \\
75 & 1.08 & 2024.29 \\
77 & 13.58 & 93.15 \\
87 & 3.88 & 380.56 \\
88 & 2.80 & 1081.05 \\
$91 A$ & 20.88 & 103.59 \\
$91 B$ & 26.50 & 63.10 \\
92 & 38.70 & 48.72 \\
94 & 505.00 & 5.10
\end{tabular}




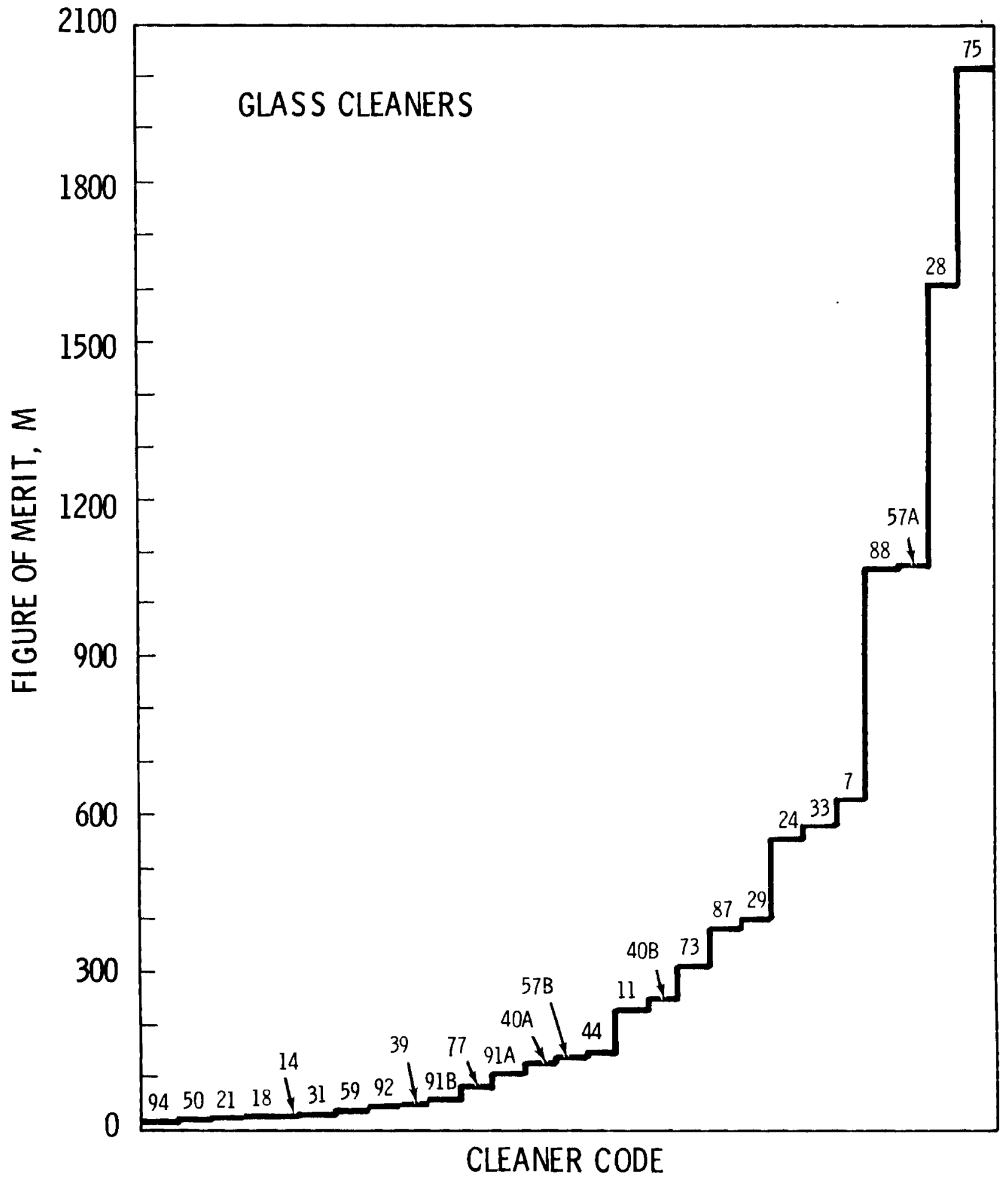

FIGURE 16. Figure of Merit for Glass Cleaners Used in Non-Contact Cleaning in Solar Application 


\section{ACKNOWLEDGMENTS}

The authors wish to thank Tim Stewart and Mike Nordmeyer for their many long hours of data gathering and analysis. 


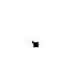


APPENDIX A

MANUFACTURERS AND DISTRIBUTORS

OF GLASS CLEANERS 
Abso-Clean Chemical Co.

17325 Lamont

Detroit, MI

(313) 366-3820

Acme Chemical Co.

2506 N. 32nd St.

Milwaukee, WI

(414) 442-6321

Aero Wash Systems, Inc. Terry Industrial Park

336 Terry Dr.

Trevase, PA

(215) $355-8025$

L. B. Allen Company, Inc.

9339 Bernice Ave.

Schiller Park, IL

(312) 678-3097

Amchem Products, Inc.

Box 33

Ambler, PA

(215) 628-1000

Ames Chemical Co.

31780 Frankl in Fairway

Farmington, MI

(313) 851-2690

Angler Chemical Co.

100 Messenger St.

Plainville, MA

(617) 695-9311

Argo \& Company, Inc.

178 Ezel1 St., P.0. Drawer 2747

Spartanburg, SC

(803) 583-9766

Barco Chemical Products Co.

703 S. LaSalle St.

Chicago, IL

(312) 427-2916
No cleaner available to meet requirements (Not applicable)

Not applicable

Not applicable

Their cleaner is an alcohol, ammonia and water mixture that would evaporate too rapidly and leave streaks, so is not applicable.

Company no longer at this location.

Not applicable

Chempol 104 is a cleaner for Kilben Glass Co. It is slightly acidic and non-alcohol based. It is good for Coilzac. A sample will be sent.

Argosheen is a synthetic, nonalcohol based rug cleaner with emulsifier and $10 \%$ petroleum content. A sample will be sent.

A mixture of agents similar to Windex is made by Procter \& Gamble. Calling Procter \& Gamble in Cincinnati concerning their Arvus wetting agent was suggested. 
Bernard's Laboratories, Inc.

1632 Walnut St.

Cincinnati, $\mathrm{OH}$

(513) 621-6924

Bestline Non-Polluting Prod., Inc.

1100 Touhy Ave.

Elk Grove Village, IL

(312) 437-2555

Boston Chemical Industries, Inc. 168 A St.

South Boston, MA

(617) 269-0555

Boyer Chemical Co.

1609 Church St.

Evanston, IL

(312) $475-1005$

CMC Laboratories Co., Inc.

122 w. Houston St.

New York, NY

(212) $675-8210$

Carhoff Co.

13404 St. Claire Ave.

P.0. Box 10480

Cleveland, $\mathrm{OH}$

(216) $541-4835$

Cello Chemical Company, Inc.

968 Easton Rd.

Warrington, $P A$

(215) 343-1250

B-15, a synthetic cleaner with chelating agents, various surfactants and drying agents, will be sent.

Not applicable

They no longer carry glass cleaners; not applicable.

A synthetic detergent that is sprayed on, let stand, and followed with a rinse was suggested. A sample will be sent.

Not applicable

Chemclean Corporation

128-05 18th Ave.

College Point, NY

(212) 445-2330

A brief outline of the problem was requested in order to work up solutions in the laboratory.

A mildly alkaline water-based butyl was suggested. No. 101, which is a mixture of amides, sodium, LAS salt, and complex phosphates, will be sent. (Glycol ether solvents need wetting agents in rinse; perhaps $0.01 \%$ rinse additive formulated with cleaner.) 
Chemical Products Co.

1213 Jackson

Omaha, NB

(402) $345-5432$

Chemtronics, Inc. 45 Hoffman Ave. Hauppauge, NY

(516) 582-3322

Claire Manufacturing Co.

7620 S. Harvard

Chicago, IL

(312) $543-7600$

Classic Chemical Co. 16th and Nickel Sts.

Camden, $\mathrm{NJ}$

(609) 964-7006

Crescent Chemical Corp.

460 Market St.

Perth Amboy, NJ

(201) 826-3630

The Drackett Co.

5020 Spring Grove Ave.

Cincinnati, $\mathrm{OH}$

(513) $632-1500$

Du Bois Chemicals

Division of Chemed Corp.

1314 Du Bois Tower

Cincinnat $\mathrm{i}, \mathrm{OH}$

(513) $762-6795$

Dytex Chemical Co.

372 Central Ave.

Pawtucket, RI

(401) 724-6300

Easterday Supply Co.

901 E. 61st

Los Angeles, CA

(213) 231-9131
A windshield cleaner concentrate that lowers surface tension was suggested. Kleenmaster, a cleaner used to clean large buildings, will be sent. The cleaner is sprayed on and does not have to be rinsed off.

It was suggested that chandelier cleaner with antistatic ingredients be used. This was also felt to be economically feasible.

Not applicable

It was suggested to use a wetting agent in the rinse or lower the surface tension of the rinse with non-ionic surfactants and follow with a rinse of demineralized water. A sample will be sent.

Not applicable

Not applicable

Flow, a Lectro-Safe solvent in which no rinsing is required, will be sent.

Not applicable

Not applicable 
Edison Chemical Co.

71 Amory

Boston, MA

(617) 442-0270

Emulso Corp.

299 Ellicott St.

Buffalo, NY

(716) 854-2889

Environmental Control Sys., Inc. 409 Washington Ave.

Baltimore, MD

(301) 296-7859

Epic Chemical, Inc.

93 Coffey St.

Brooklyn, NY

(212) 625-3180

Essential Chemicals Corp. 28391 Essential Rd.

Merton, WI

(414) 691-3000

Federal International Chemicals 1191 S. Wheeling Rd.

Wheeling, IL

(312) 541-9000

Alex C. Fergusson Co.

Spring Mill Dr.

Frazer, $P A$

(215) 647-3300

Fuld-Stalford

1354 01d Post Rd.

Havre De Grade, MD

(301) 939-1234

A. J. Funk \& Company, Inc.

1471 Timber Dr.

Elgin, IL

(312) 741-6760
An alcohol-based cleaner will be sent.

No. 999 dishwashing liquid, a nonphosphate, synthetic cleaner, will be sent. Our problem was thought to be similar to cleaning glass in dishwashers.

A sample of non-streak, non-film synthetic cleaner will be sent.

Not applicable

Cleaner No. 103, an isopropyl-based cleaner with a wetting agent, will be sent.

Not applicable

A sample of synthetic cleaner Lance will be sent.

See Cello Co.

Not applicable 
Gai1 Industries

621 4th Ave. SE

P.0. Box 1864-T

Cedar Rapids, IA

(319) 366-6241

Golden Star Polish Mfg. Co., Inc.

400 E. 10th Ave.

North Kansas City, MO

(816) 842-0233

Gold Seal Co.

P.0. Box 1698

Bismark, ND

(701) 223-4880

$\mathrm{NJ}:$ (201) 273-4990

Haviland Products Co.

421 Ann St. NW

Grand Rapids, MI

(616) 361-6691

Hillyard Chemical Co.

302 N. 4th St.

St. Joseph, MO

(816) 233-1321

Holbrook Industries, Inc.

604-T River St.

Grand River, $\mathrm{OH}$

(216) 352-2411

Howel1 Bros. Chemical Labs

5414 W. Sirard Ave.

Philadelphia, PA

(215) 477-0260

Phillip A. Hunt Chemical Corp.

Organic Chemical Division

Massasoit Ave.

P.0. Box 4249

East Providence, RI

(201) 944-4000

International Products

P.0. Box 118

Trenton, $\mathrm{NJ}$

(609) $394-5480$
Not applicable

Produce foam cleaner only; not applicable.

Chandelier cleaner recommended

(see Hylon-Hoburn Chemicals, Inc.).

A sample will be sent.

A synthetic to buffer minerals in water and get rid of hydrocarbons was suggested. Synthetic cleaners No. 153 and Topclean will be sent.

No cleaner was available to meet requirements at present, but one could be designed.

A glass detergent, One-Step Cleaner, will be sent.

Not applicable
A sample of Micro, an EDTA synthetic cleaner with a chelating agent, will be sent. 
Hylon-Hoburn Chemicals, Inc.

20 S. 2300 W. A

Salt Lake City, UT

(801) 364-6580

J. Chemical Works

602 W. 37th St.

New York, NY

(201) 656-5238

Jacks Manufacturing Co.

B St.

Mendota, MN

(612) 452-1474

Jasco Chemical Corp.

Terra Bella at Linda Vista

Mountain View, CA

(415) 968-6005

Kano Laboratories, Inc.

1079 Thompson Lane

Nashville, TN

(615) 833-4101

Klean Strip Division

P.0. Box 1879

Memphis, TN

(901) 775-0100

Knicks Mend-Rite Co.

1443 Gentry

North Kansas City, MO

(816) 842-0233

Lan-0-Sheen, Inc.

$1 \mathrm{~W}$. Water

St. Paul, MN

(612) 224-5681

Mac's, Inc.

P.0. Box 391

Dubuque, 10

(606) $329-3743$
They represeint Sparkle-Plenty Co.

Not applicable

To avoid the problem of streaks resulting from the use of ammonia, a mixture of $30-40 \%$ isopropyl, $60 \%$ soft water, and a sma 11 amount of Triton $X-100$ wetting agent was suggested.

Not applicable

Not applicable

A sample of an alcohol-based cleaner that uses ethyl glycol to increase wetting time will be sent.

Not applicable

Not applicable

Mac's 8000 glass cleaner concentrate for autos, which contains phosphates and must be diluted 1 gt. $/ 20$ gal. water, is suggested. It can be purchased at NAPA auto stores. 
Magnuson Products Corp.

Not applicable

50 Court St.

Brooklyn, NY

(212) 625-0190

Maintenance Products, Inc.

797 W. Commercial St.

Lowe 11, IN

(219) 696-6411

Manostat Corp.

519 8th Ave.

New York, NY

(212) 594-6262

Mellocraft Co.

1320 Locust

P.0. Box 567

Toledo, $\mathrm{OH}$

(419) 243-6100

Memer, Inc.

1830 Ellsworth Andus Dr. NW

Atlanta, GA

(404) $355-4580$

Merix Chemical Co.

2234 E. 75th St.

Chicago, IL

(312) 221-8242

Michelman Chemicals, Inc.

9090 Shell Rd.

Cincinnati, $\mathrm{OH}$

(513) 793-7766

Midland Laboratories, Inc.

210 Jones St.

Dubuque, 10

(319) 743-3226

Mitche11 Manufacturing Corp. P.0. Box 65

Wood River Junction, RI

(401) 364-7731

A sample of No. 346 Sprazit, an alcohol, glycol and ether cleaner, will be sent.

Most of the cleaners carried are alcohol-based and will leave a film if not wiped. A sample will be sent.

Merix 100 gal. wash concentrate with 100:1 dilution and desynthesizing agent will be sent.

Not applicable

Produce foam cleaner on $7 y$; not applicable.

Not applicable 
Mohawk Finishing Prod., Inc. Perth Rd.

Amsterdam, NY

(518) 843-1380

National Cleanser Prod. Co., Inc. 437 11th Ave.

New York, NY

(212) 563-6377

National Laboratories

Lehn \& Fink Indus. Prod. Div. 225 Summit Ave.

Montvale, $\mathrm{NJ}$

(201) 391-8500

New Haven Heat Treating

454 Grand Ave.

New Haven, CT

(203) 787-1269

Nyco Products Co.

3021 W. 36th

Chicago, IL

(312) $847-3484$

Oakite Products, Inc. 50 Valley Rd.

Berkeley Heights, $\mathrm{NJ}$

(201) 464-6900

Octagon Process, Inc.

12 Archer Ave.

Edgewater, $\mathrm{NJ}$

(201) 945-9400

Penetone Corp. 70 Hudson Ave.

Tenafly, NJ

(201) 567-3000

Puritan Chemical Co.

916 Ashby St. NW

Atlanta, GA

(404) 872-0721
Not applicable

See J. Chemical Works

Not applicable

Not applicable

Not applicable

Oakite Surfcon 300 organic acid cleaner will be brought in when available by local sales representative.

Cleaner No. 3677, which was sent to us for plastics, was suggested for use on glass also. Feedback on how it performs was requested, with the formula to be modified accordingly.

Not applicable

Glint Cleaner in a dilution of 10:1 with water will be sent. 
Reefer-Galler, Inc.

105 Hudson

Jersey City, NJ

(201) 434-1300

Reily Chemical Co.

450 Mandeville St.

P.0. Box 50372

New Orleans, LA

(504) 488-0889

Riverside Chemical Co., Inc.

River \& Rasch Rds.

North Tonawanda, NY

(716) 692-1350

Rosentha1 Cleans-Quick Corp. 30995 Industrial Rd.

Livonia, MI

(313) $341-2880$

Rothlan Corp.

P.0. Box 5074

St. Louis, MO

(314) 383-5254

Sanivan Laboratories, Inc. 222 Liberty

Camden, NJ

(609) 966-0660

Stan Sax Corp.

5659 Lauderdale Ave.

Detroit, MI

(313) $366-3820$

Sentinel Soap \& Chemical Co., Inc. 3819 Emerson Ave. S.

Minneapolis, $M N$

(612) 824-5100

E. B. Snyder Laboratories

121820 Shackamaxon

Philadelphia, PA

(215) 426-9585
Not applicable

Foampak Formula 200 will be specially formulated for us with wetting agents reduced since surface has no grease. A cationic wetting agent is used to eliminate electrostatic adhesion force.

A fluorinated solvent, Genosolve (triflorotrichloromethane - liquid freon), will be sent.

An alcohol-based cleaner will be sent.

Not applicable

A sample containing two types of alcohol and a small amount of detergent will be sent.

Not applicable

Not applicable

Not applicable 
Solar Kinetics, Inc.

147 Parkhouse St.

P.0. Box 10764

Dal las, TX

(214) 747-6519

Solventol Chemical Prod., Inc. 13177 Huron River Dr.

Romu 1us, MI

(313) 941-3800

Sparkle Plenty

625 N. Michigan

Chicago, IL

(312) $266-1700$

Sprayaway, Inc.

484 Vista Ave.

Addison, IL

(312) 628-0998

State Chemical Manufacturing Co. 3100 Hamilton Ave.

Cleveland, $\mathrm{OH}$

(216) $861-7114$

Stoners Ink Co.

Quarryville, PA

(717) $786-7355$

Sunshine Chemical Corp.

P.0. Box 17041

West Hartford, CT

(203) 232-9227

Texo Corp.

2801 Highland Ave.

Cincinnati, $\mathrm{OH}$

Trico Products Corp.

817 Washington St.

Buffalo, NY

(716) $852-5700$
Samples of SKI-500 Solar Reflector

Cleaner and SKI-5001 Solar Reflector

Rinse Agent will be sent.

GL Spray, a concentrated synthetic glass cleaner with a wetting agent and a solvent, will be sent.

A one-qt. sample of chandelier cleaner will be sent.

Not applicable

Synthetic Cleaners Nos. 222, 174, or 999, which have cationic wetting agents, will be delivered by local sales representative. (Filtering rinse water with activated charcoal to remove dissolved minerals was suggested.)

Not applicable

A synthetic that has a high-performance wetting agent, a chelating agent, and is synergistic, will be sent.

Car Wash AD, a synthetic-based cleaner, will be sent.

Not applicable 
Company Name and Address

Trio Chemical Works, Inc.

345 Scholes St.

Brooklyn, NY

Turco Products Division

24600 S. Main St.

P.0. Box 6200

Carson, CA

(213) $835-8211$

Twin Specialties Corp.

Suite 154

111 Presidential Blvd.

Bala-Cynwyd, PA

(215) 664-1744

U. S. Chemical Corp.

5400 E. 59th St.

Kansas City, MO

(816) $333-5900$

U. S. Aviex Co.

1056 Huntley Rd.

Niles, MI

(616) 683-6767

Universal Shellac \& Supply Co., Inc. 495-T W. John St.

Hicksville, NY

Water Soluble Products Div.

725 County Line Rd.

Deerfield, IL

(312) 675-1566

Western Chemical Co.

417 S. 4th

St. Joseph, MO

(816) 279-1681

Williams Chemical Corp. 3950 NW 31st Ave.

Miami, FL

(305) 633-0148

\section{Reply}

Not applicable

Samples of the cleaning concentrates Turco 5366 LPH and Turco Rinse will be sent.

A sample of Twin Super Wash wi11 be sent.

Not applicable

A sample of an ammoniated alcoholbased cleaner will be sent.

A sample of GTC-59, a water repellant, anti-static, anti-fog cleaner that produces a protective coating on glass, will be sent.

Not applicable

Not applicable

A sample of Will-Clear cleaner will be sent. 
Wis-King, Inc.

Not applicable

14 Spielman Rd.

Fairfield, NJ

(201) 227-3710

Zep Manufacturing $\mathrm{Co}$. 3008 Olympic Indus. Blvd. Atlanta, GA

(404) $355-3120$

WA: (206) 228-2100

Zoned Soap Co. 824 W. Main

Fort Wayne, IN

(219) 424-8188

Zophar Mills, Inc.

100 25th St.

Brooklyn, NY

(212) 768-0907

Samples will be sent.

Not applicable

Not applicable 


\section{APPENDIX B \\ MANUFACTURERS AND DISTRIBUTORS \\ OF PLASTICS CLEANERS}


Company Name and Address

Brulin \& Co., Inc.

P.0. Box 270B

Indianapolis, IN 46206

Chemical Products Co.

1213 Jackson

Omaha, NB

E.I. DuPont de Nemours \& Co, Inc.

Wilmington, DE 19898

Herbert Stanley Co.

Skokie, IL 60076

Kleen Chemical Manufacturing Co.

2501 N. Sheffield St.

Chicago, IL 60614

Kodak

343 State St.

Rochester, NY 14650

Merix Chemical Co.

2234 E. 75th St.

Chicago, IL

Nokomis International, Inc.

P.0. Box 4815

Hayward, CA 94540

Octagon Process, Inc.

12 Archer Ave.

Edgewater, NJ 07020

Schwartz Chemical Co., Inc.

50-01 2nd St.

Long Island City, NY

TEXO Corporation

2801 Highland Ave.

Cincinnati, $\mathrm{OH} 45212$

\section{Samples Sent}

Laminade

Kleenmaster

Alkanol WXN, Duponol WA, and ZOYNL-FCS, ZOYNL-FSN, ZOYNL-FSB

Weiman Chandelier Rinse

Space-B-K1een

Photo-Flo

Merix Cleaner

Nokomis 3

Octagon 3677 in dilutions of $1 / 2$ oz/gal and 1/4 oz/gal

$\mathrm{Rez}-\mathrm{N}-\mathrm{Cleen}$

TEXO 481 and TEXO APC 
<smiles>[Mg][Mg]</smiles> 
APPENDIX C

THE t-TEST 
The $t$ distribution test was used to evaluate the significance of the difference between the mean drop areas on a single sample. The t-test is a statistical test which takes into account both the extent of the difference between the means as well as the variability of the samples. The parameter $t$ may be defined as the ratio of the difference between the sample means to the standard error of this difference. The t-test is generally used for tests with fewer than 30 samplings per mean.

There are many methods for calculating $t$. The one used in this study is given for different sample sizes as:

$$
t=\frac{\bar{x}_{1}-\bar{x}_{2}}{s\left(\bar{x}_{1}-\bar{x}_{2}\right)}
$$

where $S\left(\bar{x}_{1}-\bar{x}_{2}\right)$ is the standard error of the difference between the two means and is defined as:

$$
S\left(\bar{x}_{1}-\bar{x}_{2}\right)=\sqrt{S^{2} \frac{N_{1}+N_{2}}{\left(N_{1} \times N_{2}\right)}}
$$

where

$$
S^{2}=\left(\frac{\sum x_{1}^{2}+\sum x_{2}^{2}}{N_{1}+N_{2}-2}\right)
$$

Here $\mathrm{S}^{2}$ is the variance and $\mathrm{N}$ represents the sample size.

Once $t$ has been calculated, the value is compared to values given in a t-table, and a decision is made to either accept or reject the null hypothesis. In this case the null hypothesis indicates that the means are the same. The criterion used in this analysis is to reject the null hypothesis if $p$ (found from table) is equal to or less than 0.05, and regard the hypothesis as tenable if $p$ is larger than 0.05 . This corresponds to a $95 \%$ confidence interval for the data. 
DISTRIBUT ION

No. of

Copies

OFFSITE

1 DOE Chicago Patent Group 9800 South Cass Ave. Argonne, IL 60439

A. A. Churm

6 DOE Division of Solar Technology 20 Massachusetts Ave. Washington, DC 20545

G. Braun

M. U. Gutstein

G. M. Kaplan

L. Melamed

J. E. Rannels

J. Weissinger

1 DOE Office of Solar Application

20 Massachusetts Ave. Washington, DC 20545

A. C. Min

27 DOE Technical Information Center

(UC 62)

$1 \quad$ Haviland Products Co. 421 Ann St. NW Grand Rapids, MI 49504

2 Jet Propulsion Laboratory 4800 Oak Grove Dr. Pasadena, CA 92647

M. Adams

W. Carroll
No. of

Copies

OFFSITE

2 McDonnel1 Douglas

Astronautics Co. 5301 Bolsa Ave. Huntington Beach, CA 92647

C. R. Easton

M. Sheratle

8 Sandia Laboratories Box 5800 A1buquerque, NM 87115

D. Arvisue - STTF

E. Beauchamp

R. Champion

J. Leonard

B. Marshal1

J. Otts - STTF

R. Pettit

L. Rainhart

$4 \quad$ Sandia Laboratories Livermore, CA 94550

C. Mavis

A. Skinrood

W. Wilson

6 Solar Energy Research Institute 1536 Cole B1vd. Golden, CO 80401

B. Butler

P. Cal1

T. Coyle

A. Czanderna

K. Masterson

S. Pullman

1 U.S. Avinex Co.

1056 Hunt Tey Rd. Niles, MI 49120 


\section{DISTRIBUTION (contd.)}

No. of

Copies

OFFSITE

1

Mr. Applebaum

International Products

P.0. Box 118

Trenton, NJ 08607

1 D. Argo

Argo \& Company, Inc.

P.0. Drawer 2747

Spartanburg, SC 29304

$1 \quad$ P. Bender

Ford Motor Co.

Glass Division

P.0. Box 43343

Detroit, MI 48243

$1 \quad$ F. Bradley

Classic Chemical

16th \& Nickel Sts.

Camden, NJ 08105

1 L. Brothers

Dubois Chemicals

Div. of Chemed Corp.

1314. Dubois Tower

Cincinnati, OH 45202

$1 \quad$ N. Cantos

Essential Chemicals Corp. 28391 Essential Rd.

Merton, WI 53056

1 C. Catacchio

Bestline Non-Polluting

Products, Inc.

1100 Touhy Ave.

Elk Grove Village, IL 60007

$1 \quad$ W. Durkin

Universal Shellac \&

Supply Co., Inc.

495-T W. John St.

Hicksville, NY 11803
No. of

Copies

OFFSITE

1 R. A. England

Martin Marietta

MS S0403

P.0. Box 179

Denver, C0 80201

1 H. E. Felix

Solaramics, Inc.

1301 El Segundo B1vd.

E1 Segundo, CA 90245

1 D. Flesher

Economics Lab

840 Sibley Memorial "ghway

St. Paul, MN 55118

1 C. R. Frownfelter

PPG Industries, Inc.

One Gateway Center

Pittsburgh, PA 15222

$1 \quad$ R. Gillett

Boeing Eng. \& Construction

MS $9 A-46$

P.0. Box 3707

Seattle, WA 98124

$1 \quad$ C. Guss

Chemical Products Co.

1213 Jackson

Omaha, NE 68102

1 E. Heinzelman

Solventol Chemical

Products, Inc.

13177 Huron River Dr.

Romulus, MI 48174

1 J. S. Herbert

ASG Industries, Inc.

P.0. Box 929

Kingsport, TN 37662 
PNL-2969

UC -62

DISTRIBUTION (contd.)

No. of

Copies

OFFSITE

1 P. L. Hoffman

Prog. Planning \& Analysis

Battelle Energy Program

Battelle-Columbus Labs.

505 King Ave.

Columbus, $\mathrm{OH} 43201$

1 D. Holdridge

Swedlow, Inc.

12122 Western Ave.

Garden Grove, CA 92645

1 R. H. Horton

Energy Systems

One River Rd.

Schenectady, NY 12345

1 J. Houghtby

Rosenthal Cleans-Quick Corp. 30995 Industrial Rd.

Livonia, MI 48150

1 S. Kaufmann

Sunshine Chemical Corp.

P.0. Box 17041

West Hartford, CT 06117

$1 \quad$ E. Korte

Texo Corp.

2801 Highland Ave.

Cincinnati, $\mathrm{OH} 45212$

1 W. Larsson

Angler Chemical Co.

100 Messenger St.

Plainville, MA 02762

1 Ms. McHugh

Sanders Associates

MS MER12-1214

95 Canal St.

Nashua, NH 03061
No. of

Copies

OFFSITE

1 W. D. Mitchell

Solaramics, Inc.

1301 El Segundo Blvd.

El Segundo, CA 90245

1 G. R. Morgan

Rocketdyne

AA95

6633 Canoga Ave.

Canoga Park, CA 91304

1 R. P. Mozzer

Insolar, Inc.

P.0. Box Z

Port Jervis, NY 12771

1 E. Nelson

ACUREX Corp.

485 Clyde Ave.

Mountain View, CA 94042

1 S. Petrosky

Twin Specialities Corp.

Suite 154

111 Presidential Blvd.

Bala-Cynwyd, PA 19004

$1 \quad$ Mr. Richmond

Klean Strip Div.

P.0. Box 1879

Memphis, TN 38101

1 I. B. Rickling

Florida Solar Energy Center Library 300 State Rd. 401

Cape Canaveral, FL 32920

$1 \quad$ W. Rogers

Dept. of Mech. Engineering

Rensselaer Poly. Inst.

JEC 2049

Troy, NY 12181 
DISTRIBUTION (contd.)

No. of

Copies

OFFSITE

1 J. Ross

Hillyard Chemical Co. 302 N. 4th St.

St. Joseph, MO 64501

$1 \quad M r$. Schwartz

Alex C. Fergusson Co. Spring Mill Dr.

Frazer, PA 19355

1 A. F. Shoemaker

Corning Glass Works

Corning, NY 14830

$1 \quad$ G. Siegle

CMC Laboratories Co., Inc.

122 W. Houston St.

New York, NY

1 M. Sine

Environmental Control

Systems, Inc.

409 Washington Ave.

Baltimore, MD 21227

1 E. Sommeman

Merix Chemical Co.

2234 E. 75th St.

Chicago, IL 60649

1 G. Sturgen

Emulso Corp.

299 Ellicott St.

Buffalo, NY 14203

1 H. R. Swift

Libby Owens Ford Co.

Technical Center

1701 E. Broadway

Toledo, $\mathrm{OH} 43605$

1 R. Taylor

Arizona Public Service Co.

P. 0. Box 21666

Phoenix, AZ 85036
No. of

Copies

OFFSITE

1

K. Thompson

Reily Chemical Co.

P.0. Box 50372

New Orleans, LA 71078

1 W. Toml inson

Environmental Library

University of Montana

758 Eddy St.

Missoula, MT 59812

1 L. Van Pyke

Sanivan Laboratories, Inc.

222 Liberty

Camden, NJ 08104

1 R. R. Walters

E. Systems

P.0. Box 6118

Dallas, TX 75222

1 M. Weast

Turco Products Div.

P.0. Box 6200

Carson, CA 90749

$1 \quad$ C. Wienfield

Edison Chemica? $\mathrm{Co}$.

71 Amory

Boston, MA

1 J. Wiggan

Mellocraft Co.

1320 Locust

P.0. Box 567

Toledo, $\mathrm{OH} 43601$

1 S. Zwerdling

Northeast Solar Energy Center

70 Memorial Dr.

Cambridge, MA 02142 
DISTRIBUTION（contd.)

No. of

Copies

ONSITE

2 DOE Richland Operations

Office

H. E. Ransom

R. Stewart

$40 \quad$ Pacific Northwest Laboratory

W. J. Coleman

K. Drumheller

H. L. Hampton (5)

M. A. Lind (25)

J. M. Rusin

Pubtishing Coordination (2)

Technical Information (5) 
